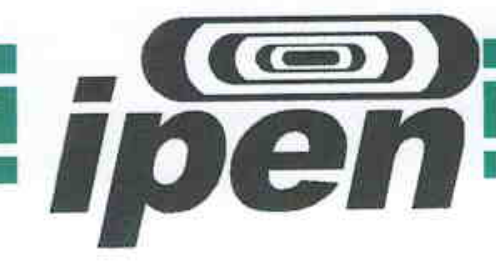

\title{
AUTARQUIA ASSOCIADA A UNIVERSIDADE DE SÃO PAULO
}

Emprego da radiação gama do Cobalto-60 na desinfestação de alguns tipos de rações para alimentação de animais de pequeno porte

\section{Paula Bergamin Arthur}

Dissertação apresentada como parte dos requisitos para obtenção do Grau de Mestre em Ciênclas na Area de Tecnologia Nuclear - Aplicaçőes

Orientadora:

Profa. Dra. Anna Lucia H. C. Villavicencio 


\title{
DEDICATÓRIA
}

\author{
Dedico aos meus pais Valter Arthur \\ e Cleide Roseli Bergamin Arthur, pelos ensinamentos transmitidos \\ durante toda a trajetória da minha vida.
}

E

Em memória aos meus avós

Paulo Arthur e Rosina Bonato Arthur

e

Antonio Bergamin e Emilia Beluco Bergamin 


\section{AGRADECIMENTOS}

Agradeço a Deus por iluminar sempre meu caminho, pelos pensamentos, e por me dar saúde, paciência e sabedoria para o desenvolvimento deste trabalho.

A Profa. Dra. Anna Lucia Villavicencio, minha estimada orientadora, pela oportunidade, pela paciência e por acreditar nesse trabalho, agradeço pelas dicas, sugestões e criticas.

Ao meu pai Prof. Dr. Valter Arthur, pelo apoio, incentivo, paciência, amor, força e atenção dedicada durante a minha vida e pela co-orientação na execução deste trabalho.

Aos familiares em especial a minha madrinha Dalva e a minha prima Roberta que me deram apoio, incentivo e atenção.

A Profa. Dra. Solange Guidolin Canniatti Brazaca, pelas sugestões, criticas e ensinamentos durante a participação do meu seminário de área e na defesa da dissertação.

A Dra. Suely Salumita Haddad Franco, pelas sugestões, criticas e ensinamentos durante a participação durante a defesa da dissertação.

Ao Prof. Dr. Claudio Lima de Aguiar, pelos conhecimentos e, ensinamentos transmitidos.

Agradeço ao meu namorado Rodrigo Sebastião, pela paciência, incentivo, otimismo e companhia nas horas boas e ruins, durante todo o período de desenvolvimento deste trabalho.

A técnica Lucia Cristina Aparecida Silva Santos e estagiários e pós-graduandos do laboratório de Radiobiologia e Ambiente do CENA/USP, pela contribuição ativa, pelas dicas, sugestões e ajuda durante o desenvolvimento deste trabalho.

Aos professores do Curso de Pós-Graduação do IPEN pelas informações e conhecimentos transmitidos que contribuíram para a execução deste trabalho.

Ao Programa de Pós-Graduação de Ciências e Tecnologia Nuclear Aplicações do IPEN pela oportunidade concedida.

A todos os funcionários do Programa de Pós-Graduação do IPEN.

Ao CNPq pela bolsa e auxilio concedido durante o desenvolvimento desta pesquisa. 


\title{
EMPREGO DA RADIAÇÃO GAMA DO COBALTO-60 NA DESINFESTAÇÃO DE ALGUNS TIPOS DE RAÇÕES PARA ALIMENTAÇÃO DE ANIMAIS DE PEQUENO PORTE
}

\author{
PAULA BERGAMIN ARTHUR \\ RESUMO
}

As pragas como besouros, ácaros, traças e fungos dentre outros, geralmente infestam produtos armazenados como: grãos, farelos, farinhas, café, fumo, frutas secas, rações animais, especiarias, plantas desidratadas, causando a depreciação visual e promovendo a deterioração dos produtos. Devido a isso a presente pesquisa teve como objetivo a utilização da radiação gama na desinfestação de alguns tipos de rações utilizadas para alimentação de animais de pequeno porte. No primeiro ensaio foram utilizadas embalagens de amostras grátis medindo $10 \mathrm{~cm}$ x $20 \mathrm{~cm}$ com capacidade de 70 gramas de substratos (ração) com 4 tipos de marcas existentes no comercio: (1), (2), (3) e (4). Cada tratamento constou de 10 repetições, que foram irradiadas com as doses de: 0 (controle) 0,5; 1,0 e 2,0 kGy, para se fazer a desinfestação das amostras. Após a irradiação (desinfestação) todas as embalagens irradiadas e mais a testemunha foram acondicionadas em caixas plásticas de $80 \mathrm{~cm} \times 50 \mathrm{~cm}$ com tampa, onde foram liberados os insetos Lasioderma. serricorne, Plodia interpuctella, Sitophilus zeamais e Sitophilus oryzae, num total de 400 para cada caixa e mantidas em sala climatizada com $27 \pm 2^{\circ} \mathrm{C}$ e umidade relativa de $70 \pm 5 \%$. No segundo ensaio foram utilizadas embalagens confeccionadas com os materiais das embalagens do primeiro ensaio. Cada embalagem foi feita de $10 \mathrm{~cm} \times 15 \mathrm{~cm}$, com capacidade de 30 gramas de substratos (ração). Em cada repetição foi inoculado 10 insetos de cada espécie, num total de 400 insetos por caixa. As embalagens com substrato e inseto foram vedadas em seladora comercial, e irradiadas com as doses de: 0 (controle) 0,5; 1,0 e 2,0 kGy,. As embalagens irradiadas e a testemunha foram mantidas em sala climatizada já citada anteriormente. As contagens do número de insetos e furos nas embalagens foram feita após 60 dias. Concluiu-se que a embalagem da ração tipo número 4, foi a única susceptível ao ataque das espécies de insetos. A dose de 0,5 kGy foi suficiente para induzir a esterilização e conseqüentemente a desinfestação de todas as rações estudadas. 


\section{APPLICATION OF THE GAMMA RADIATION OF THE COBALT-60 IN DISINFESTATION OF SOME TYPES OF RATIONS FOR FEEDING OF SMALL ANIMALS}

\section{PAULA BERGAMIN ARTHUR}

ABSTRACT

The pests as beetles, mites, moths and mushrooms among other, usually infest products stored as: grains, crumbs, flours, coffee, tobacco, dried fruits, animal rations, spices, dehydrated plants, causing the visual depreciation and promoting to deterioration of the products. The present research had as objective the use of the gamma radiation in the disinfestation of some types of rations used for feeding of animals of small size. In the first experiment packing of free samples were used measuring $10 \mathrm{~cm} \times 20 \mathrm{~cm}$ with capacity of 70 grams of substrate (ration) with 4 types of existent marks in the trade: (1), (2), e (3), and (4). Each treatment consisted of 10 repetitions, that were irradiated with doses of: 0 (control) 0,$5 ; 1,0$ and 2,0 kGy, to do the disinfestation of the samples. After the irradiation (disinfestation) of the all irradiated packing and more the control was conditioned in plastic boxes of $80 \mathrm{~cm} \mathrm{x}$ $50 \mathrm{~cm}$ with cover, where the insects were liberated Lasioderma. serricorne, Plodia interpuctella, Sitophilus zeamais and Sitophilus oryzae, in a total of 400 for each box and maintained at room acclimatized with $27 \pm 2^{\circ} \mathrm{C}$ and relative humidity of $70 \pm 5 \%$. In the second experiment packing were used made with the materials of packing of the first experiment. Each packing was made of $10 \mathrm{~cm} \times 15 \mathrm{~cm}$, with capacity of 30 grams of substrate (ration). In each repetition was inoculated 10 insects of each species, in a total of 400 insects for experiment per box. The packing with substrate and insect, were stamped in commercial machine and irradiated with doses of: 0 (control) 0,5; 1,0 and 2,0 kGy. The irradiated packing and the control were maintained at room acclimatized same the mentioned in the first experiment. The counting of the number of insects and holes in the packing were made after 60 days. Concluded that only the packing of the ration type number 4 was susceptive to attack of all species of insects. The dose of 0,5 kGy was sufficient to induce the sterilization and consequently the disinfestation of all studied rations. 


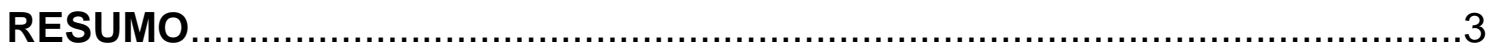

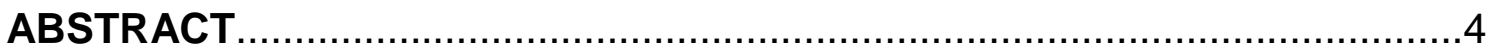

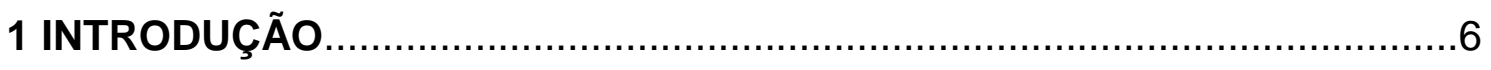

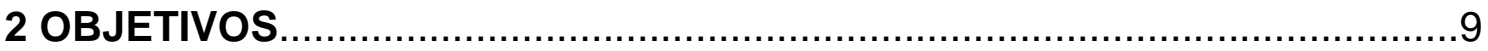

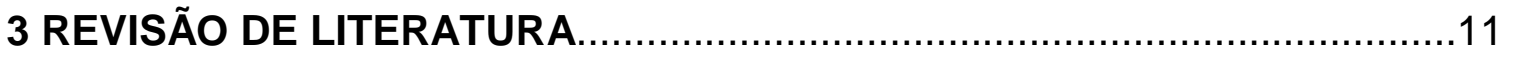

3.1 Controles de pragas de grãos e produtos armazenados..........................11

3.2 Características das pragas.............................................................. 12

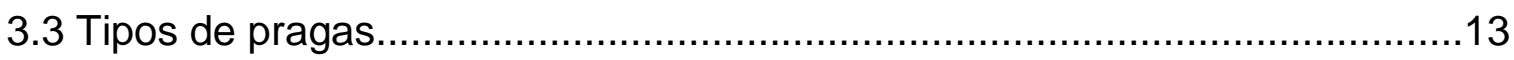

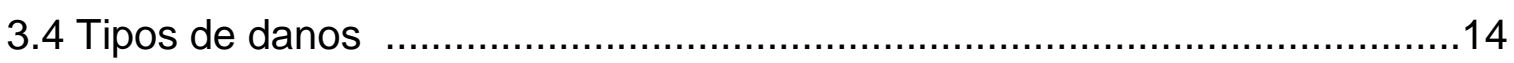

3.5 Principais pragas dos grãos e produtos armazenados ............................14

3.6 Métodos de controle..............................................................................

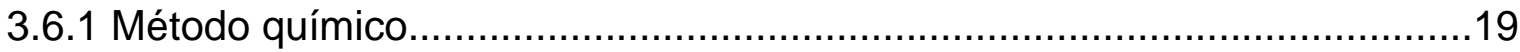

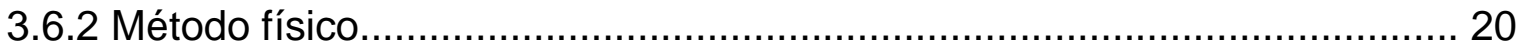

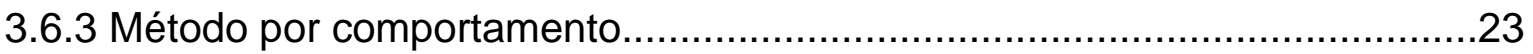

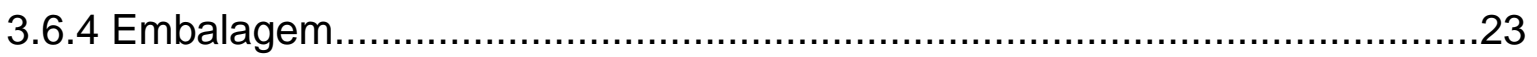

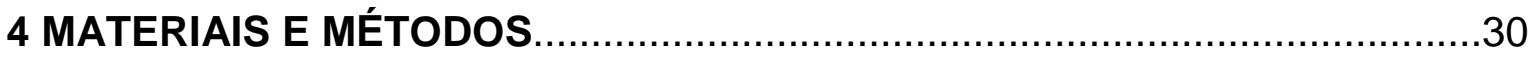

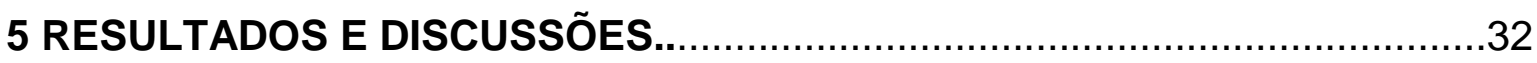

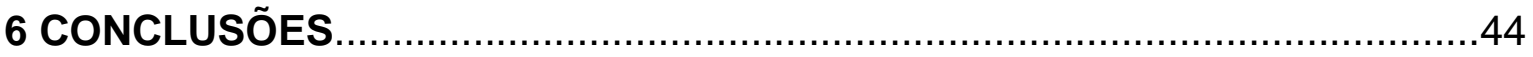

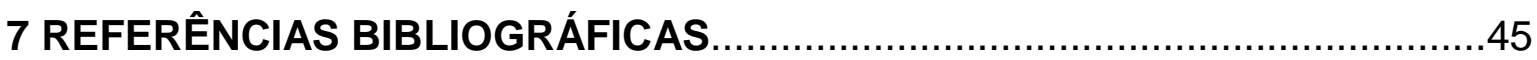




\section{INTRODUÇÃO}

Os alimentos secos a base de cereais e grãos são produtos valorizados por apresentarem aparência e sabor característicos. Porem, na maioria das vezes, eles se apresenta contaminados com altos níveis de bactéria, fungos e insetos que, se não controlados, acabam resultando em rápida deterioração dos alimentos, podendo causar sérios problemas a saúde do consumidor (MARCOTTE, 2003).

Segundo Gurkin (2001) o comércio de alimentos para animais em lojas de varejo, alcançaram US\$11,1 bilhões em 2000 nos Estados Unidos. O mercado brasileiro de alimentos para pequenos e médios animais, conhecidos como pet food movimenta algo em torno de US\$ 9,3 bilhões/ano, que responde por 1,8\% do PIB e no mundo esse número chega a US\$ 30 bilhões (SINDIRAÇÕES, 2012). O Brasil é considerado o terceiro maior mercado de pet food do mundo (HERBARIO, 2012). A produção brasileira de alimentos balanceados para animais é uma das maiores do mundo, perdendo apenas para Estados Unidos e China (SINDIRAÇõES, 2012).

Essas lojas de pet food alem do comercio de rações geralmente também comercializam mix de cereais, elaborados com sementes, legumes e cereais secos de forma processada ou inteira, utilizado para a alimentação de roedores e outros animais. Também comercializam outros produtos para alimentação de outros animais como a semente de girassol, alimentos extrusados ( alimentos elaborados em alta pressão e temperatura), farinhas, farelos, alpiste, painço etc. Geralmente estes produtos são suscetíveis ao ataque de insetos pragas (HAINES e PRANATA, 1982; RAMOS, 2009).

As pragas de grãos e produtos armazenados (GEPA) consistem em um problema permanente nessas lojas, depreciando os produtos e causando danos e prejuízos econômicos (ARTHUR, et al., 2012).

As rações geralmente são constituídas de uma elevada concentração de fibra, especialmente dos produtos de menor valor agregado, e podem afetar os outros tipos de ingredientes empregados. Nela existe uma maior participação de farelos 
vegetais ricos em fibra, como farelo de trigo (11\%), farelo de arroz (11\%) e farelo de soja (6,5\%), utilizados para reduzir o custo do produto. Devido a isso foram encontradas diferenças importantes na composição nutricional dos alimentos econômicos, standard e super-premium, constatando-se o não cumprimento dos rótulos em parte dos alimentos avaliados e inadequações na composição nutricional de produtos (CARCIOFI et al., 2006; RAMOS, 2009).

Segundo o Sindicato Nacional da Indústria de Alimentação Animal projeta crescimento de 2,8\% em 2012, em comparação ao ano anterior, com produção de 66,2 milhões de toneladas de ração e 2,58 milhões de toneladas de suplementos minerais. Em 2011, o setor cresceu 5,2\%, movimentou R $\$ 40$ bilhões em insumos e produziu 64,5 milhões de toneladas de ração e 2,35 milhões de suplementos minerais. Apenas no primeiro trimestre de 2012, a produção de rações alcançou 14,9 milhões de toneladas, recuo de $2 \%$ quando comparado ao que foi produzido de janeiro a março do ano passado. Os setores das rações seguem pressionados pelo preço das commodities que ainda continuam sendo sustentados pelos custos de produção dos alimentos. A redução do preço do milho no início de ano acentuada pela produtividade recorde da safrinha corrobora a expectativa de média abaixo da verificada no ano passado, todavia a subida forte nas cotações desde meados de 2010 alcançou 54 pontos percentuais até março de 2012 e continua impactando sobremaneira o custo de produção das atividades pecuárias. O farelo de soja, por sua vez, já aumentou quase $40 \%$ até abril desse ano por conta da menor liquidez internacional, enquanto o salário mínimo onerou a folha de pagamentos pela amplitude do reajuste e intensidade de mão de obra empregada, completa. As rações para cães e gatos foi uma das que mais aumentaram a sua produção de 2011 para 2012 sendo de 6,1\% (SINDIRAÇÕES, 2012).

Pragas como besouros, ácaros, traças e fungos dentre outros, geralmente infestam produtos armazenados como: grãos, farelos, farinhas, café, fumo, frutas secas, rações animais, especiarias, plantas desidratadas, causando a depreciação visual e promovendo a deterioração dos produtos ( CAMPOS e ZORZENON, 2006) citada por (RAMOS, 2009), (ARTHUR et al., 2012). 
Os carunchos, besouros e gorgulhos, pertencentes á ordem Coleóptera são os insetos que atacam e danificam esses produtos armazenados (CAMPOS, 2005). Esses insetos pragas dependendo do índice de infestação podem causar sérios prejuízos aos produtos tais como: perda de peso e desvalorização comercial, perda de valor nutritivo, contaminação pela penetração de outros organismos como fungos através de galerias deixadas por eles, presença de fungos, bolores e bactérias entre outros (MAGALHÃES e CARVALHO, 1998) citado por (RAMOS, 2009), (FOLLETT, et al., 2013).

Algumas medidas de controle são adotadas visando solucionar os danos e perdas ocasionadas por pragas tais como: boas práticas de armazenamento, monitoramento das pragas e tratamento químico, este por sua vez, acabam causando alguns danos, além da resistência dos insetos aos princípios ativos dos produtos químicos, devido a esses problemas, existe a necessidade de métodos de controle mais eficientes com menor custo. A irradiação de alimentos por inúmeros fatores vem se apresentando como a melhor solução no controle de pragas de grãos e produtos armazenados (RAMOS, POTENZA e ARTHUR, 2009; ARTHUR et al., 2012; FOLLETT, et al., 2013; HALLMAN, 2013).

A primeira utilização das radiações ionizantes em insetos foi realizada por Hunter em (1912) quando irradiou Sitophilus oryzae com raio $X$, mas não obteve resultados satisfatórios. Os resultados promissores só foram obtidos por Runner em (1916) que utilizou raios X para controlar Lasioderma serricorne, praga do tabaco armazenado. A partir de 1950 houve um grande avanço nesse tipo de pesquisa. Alguns fatores como a descoberta da resistência de certas pragas aos produtos químicos, o desequilíbrio biológico e os problemas toxicológicos causados por estes produtos, contribuíram para esse avanço. A irradiação dos produtos armazenados pode solucionar esses tipos de problemas, uma vez que não induz o aparecimento de resistência (HOSSAIN, BROWER e TILTON, 1972) e nem resíduos (ARTHUR et al., 1973; ARTHUR, 1985; ARTHUR, 1997; ARTHUR et. al., 2012; WIENDL et al., 1973 e 1974; FOLLETT, et al., 2013; HALLMAN, 2013).

Na conservação de grãos e produtos armazenados, muitos tipos de radiações continuam sendo estudadas como: as radiações gama, infravermelhas, raios $\mathrm{X}$, 
microondas, etc. Devido a necessidade de melhor conservação com tecnologia moderna e avançada de alta eficiência, baixo custo e ausência de efeitos colaterais, a radiação gama vem se tornando a solução mais viável. Esse processo consiste em desinfestar os grãos com uma determinada dose de radiação, inibindo a reprodução, ou mesmo causando a morte dos insetos infestantes (BARBOSA, 2010; RAMOS, 2009; ARTHUR et. al., 2012; FOLLETT, et al., 2013; HALLMAN, 2013). 


\section{OBJETIVOS}

A presente pesquisa teve como objetivos:

- Utilizar a radiação gama do Cobalto-60 para desinfestação de alguns tipos de rações utilizadas para alimentação de animais de pequeno porte

- Avaliar alguns tipos de embalagens quanto à resistência ao ataque de insetos. 


\section{REVISÃO DE LITERATURA}

\subsection{Controle de pragas de grãos e produtos armazenados}

Segundo Gallo et al., (1970), (1988), Campos e Zorzenon (2006) e Lorini et al., (2010) a qualidade das sementes em especial a fisiológica podem ser afetadas pela ação de diversos fatores entre eles as pragas dos grãos e produtos armazenados, geralmente os grãos são atacados pelos insetos tanto antes da colheita no campo como nos armazéns e podem reduzir consideravelmente os valores qualitativos e quantitativos dos grãos. Devido a isso o produtor deve se preocupar tomando medidas de controle para evitar que isso venha a ocorrer, e a principal delas é aplicação de produtos químicos.

De acordo com Pacheco e Paula (1995), Campos (2005), Campos e Zorzenon (2006), e Lorini et al., (2010) os insetos que mais danos causam aos grãos e produtos armazenados são os Coleópteros ( onde estão incluídos os carunchos, besouros e gorgulhos) e os Lepidópteros (mariposas, borboletas e traças) nestas duas ordens de insetos é que se encontram as espécies de maior importância econômica como pragas, pois são causadoras dos maiores danos aos produtos agrícolas.

Segundo Gallo et al., (2002) e Lorini et al., (2010) geralmente os coleópteros (carunchos, besouros e gorgulhos) são insetos de tamanho pequeno e possuem 0 primeiro par de asas (élitros) são resistentes, e se movimentam em espaços reduzidos no interior da massa de grãos armazenada. Os lepidópteros (mariposas, borboletas e traças) geralmente são insetos maiores, possuem dois pares de asas membranosas, com menor resistência, devido a isso sua movimentação fica mais limitada na massa dos grãos armazenados, ficando seu ataque restrito às superfícies dos grãos e sacarias (RAMOS, 2009).

A maioria das pragas dos grãos e produtos armazenados é cosmopolita, e geralmente suas densidades populacionais está sempre acima do nível do dano 
econômico, isto porque os grãos já vêm infestados do campo e se não forem controladas aumentam assustadoramente (GALLO et al., 1970; MANEJO INTEGRADO, 2012).

Devido à alta capacidade de reprodução dos insetos que atacam os produtos armazenados, em condições favoráveis de temperatura e umidade, e dependendo do número de insetos infestantes podem provocar a deterioração total dos produtos, porque as larvas desses insetos conseguem consumir grandes quantidades de alimentos. Em condições adversas sua fase intermediaria (ovo, larva e pupa) podem entrar em diapausa, ou seja, repouso completo até que as condições voltem ao normal (BORROR e DELONG, 1988), citado por (RAMOS, 2009).

Segundo Magalhães e Carvalho (1988) os principais prejuízos aos GEPA por essas pragas são: dano fisiológico, perda de peso, desvalorização comercial, perda do valor nutritivo, contaminação pela penetração de outros organismos como fungos através de aberturas deixadas pelas pragas, citado por (RAMOS, 2009).

\subsection{Características das pragas}

De acordo com Gallo et al., (2002), Campos e Zorzenon (2006) e Lorini et al., (2010) a alta capacidade de proliferação das pragas de grãos e produtos armazenados ocorre devido ao elevado potencial biótico. Nos depósitos as condições climáticas são ótimas para o seu desenvolvimento, e em pouco tempo, se transformem em uma alta população consequentemente atingindo o nível de dano econômico. Por esse motivo é de extrema importância o controle eficiente das infestações iniciais. Geralmente ocorre infestação cruzada, é a capacidade dos insetos de infestar os produtos tanto no campo como nos depósitos. Algumas espécies de insetos são polifagas e têm a capacidade de atacar diversos produtos, permitindo com que essas pragas se desenvolvam mesmo na ausência do produto especifico, não sendo afetados pela rotatividade dos produtos nos depósitos, citados por (RAMOS, 2009). 


\subsection{Tipos de pragas}

Segundo Gallo et al., (2002), Lorini, (2001), Lorini (2002a) e Campos e Zorzenon (2006) os insetos considerados pragas de produtos armazenados, são classificados conforme os hábitos alimentares: primárias e secundarias. Primarias atacam semente e grãos inteiros, denominadas de pragas primárias internas e externas. As pragas primárias externas destroem a parte exterior do grão conhecida como casca e, posteriormente, alimentam-se da parte interna, sem se desenvolverem no interior do grão atacado, favorecendo o ataque das pragas incapazes de destruir a parte externa dos grãos. As primárias internas são dotadas de mandíbulas desenvolvidas, são capazes de perfurar e penetrar nos grãos alimenta-se do conteúdo interno, e completam o ciclo evolutivo no interior do grão, são as mais prejudiciais, e facilitam o ataque de outros insetos. Já as secundárias não atacam grãos inteiros, somente os quebrados ou danificados. Essas pragas possuem capacidade de se multiplicar rapidamente e por isso causam prejuízos elevados, infestam praticamente todos os grãos armazenados, e os subprodutos, como farinhas, rações e farelos. Pragas associadas são aquelas que se alimentam dos detritos e fungos e não chegam a atacar os grãos, mas esses insetos contribuem prejudicando a qualidade e o aspecto dos produtos armazenados, citados por (RAMOS, 2009).

\subsection{Tipos de danos}

Segundo Gallo et al., (2002) e Campos e Zorzenon (2006) com relação aos danos causados pelas pragas aos produtos armazenados podem ser qualitativos ou quantitativos. Os qualitativos são caracterizados pelas alterações ocasionadas na qualidade do produto, devido à diminuição do valor nutricional; desvalorização comercial; diminuição do grau de higiene pela presença de insetos, ovos, larvas etc, e pela perda da qualidade de farinhas para a panificação. Danos quantitativos são caracterizados pela perda de peso causada pelas galerias abertas pelos insetos nos grãos. E danos às sementes que são caracterizados principalmente pela perda do poder germinativo, devido à destruição do embrião das sementes, citados por (RAMOS, 2009). 


\subsection{Principais pragas de produtos armazenados}

Como citado anteriormente, entre os insetos que atacam os produtos armazenados, os pertencentes às Ordens Coleóptera e Lepidóptera compreendem as espécies de maior importância, devido a perda econômica que elas podem ocasionar (PACHECO e PAULA, 1995, CAMPOS e ZORZENON, 2006) citados por RAMOS, 2009).

Lasioderma serricorne (Fabricius, 1792) (Coleoptera: Anobiidae) caruncho ou besourinho do fumo (figura1) e danos causados (figura 2).

A Lasioderma serricorne é um pequeno caruncho que mede cerca de 2 a 3 $\mathrm{mm}$ de comprimento. A cabeça se apresenta parcialmente coberta pelo protórax, com antenas serrilhadas à partir do quarto segmento e bem nítidas. Os élitros cobrem totalmente o abdômen e não são estriados. O corpo é ovalado e possui a coloração castanho-avermelhado, recoberto por pêlos bem claros. Quando em repouso ou perturbado, adquiri aspecto de um grão convexo, dobrando a cabeça e recolhendo as pernas (GALLO et al., 1970; GALLO et al., 1988: GALLO et al., 2002; LORINI et al., 2010).

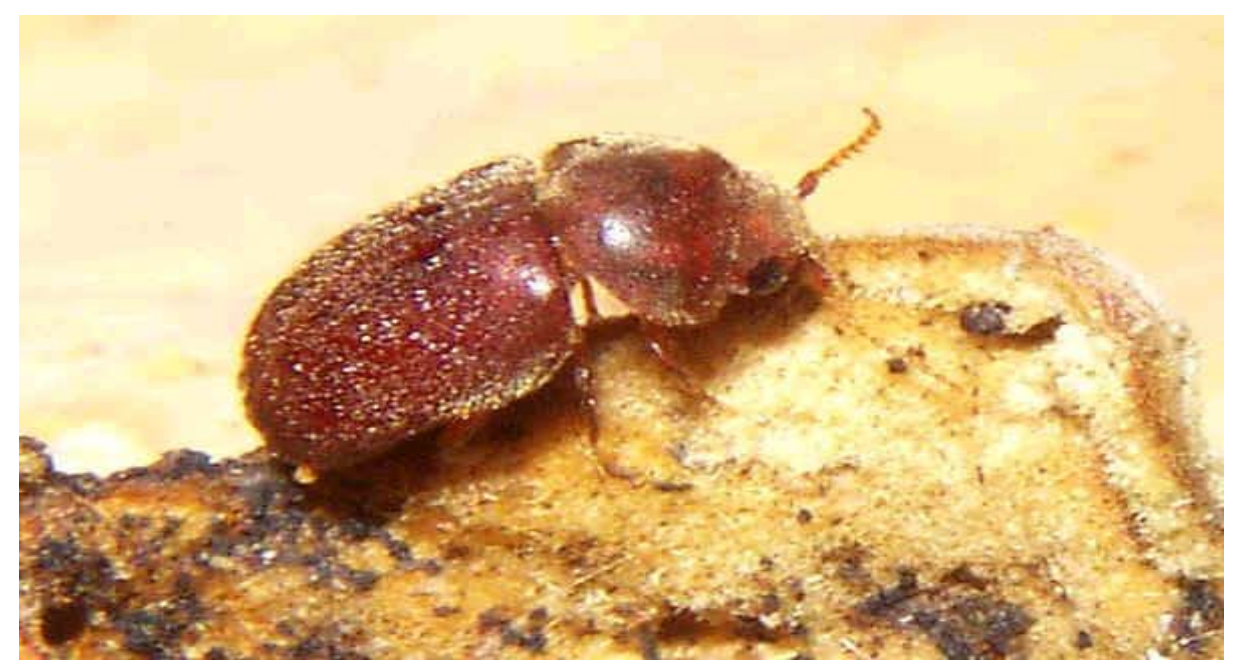

Figura 1. Lasioderma serricorne Fonte: httpwww.termapest.co.uk/id17.html 


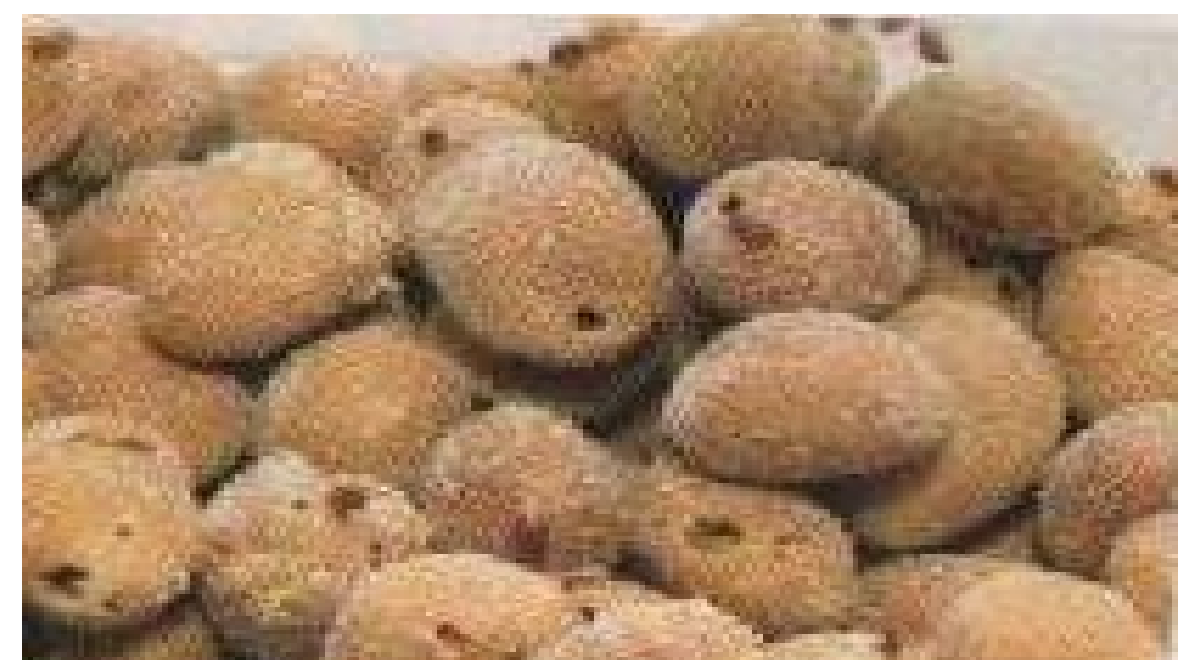

Figura 2 - Danos de Lasioderma serricorne em amendoim salgado (Campos e Zorzenon, 2006).

O inseto adulto não se alimenta e vive de 2 a 4 semanas e, é nessa fase que ele consegue perfurar embalagens plásticas e de papel. O número médio de ovos por fêmea é cerca de 40 a 100, que são colocados nos alimentos infestados. As larvas emergem entre 6 e 10 dias, o estágio larval dura de 5 a 10 semanas e nesse estágio as larvas se afastam da luz (KURTZ e HARRIS, 1962). Sua coloração é branco-leitosa, recoberta de finos pêlos. Após a eclosão, são ágeis e escavam galerias cilíndricas no produto infestado (GALLO, et al., 1970; KURTZ e HARRIS, 1962) citados por ( RAMOS, 2009). Segundo Mound (1989) as larvas são as grandes responsáveis pelos danos, já que os adultos não se alimentam.

Segundo Kurtz e Harriz (1962) o período da fase de pupa dura entre 2 a 3 semanas. Nesse estágio medem aproximadamente $4 \mathrm{~mm}$ de comprimento, possui coloração similar a larva e apresenta alguns apêndices visíveis. O ciclo de evolutivo é de 60 a 90 dias, de acordo com a temperatura e a disponibilidade de alimento (BIOCONTROLE, 2012).

Segundo Gallo et al., (1970), (1988) e (2002) a Lasioderma serricorne (F.) é incapaz de atacar plantas vivas. Mas é considerada a praga mais prejudicial do tabaco armazenado, devido a isso recebeu o nome popular de caruncho do fumo. Também ataca produtos armazenados como: farelo, farinhas, grãos, arranjos florais, amendoins, colorau, páprica, plantas desidratadas, ração para animais, pão e frutas secas causando deterioração, redução de peso e alterações estruturais desses 
alimentos e de acordo com causam também danos indiretos, devido às perfurações ocasionadas pela infestação, facilitando a penetração de microorganismos e ácaros (MAGALHAES e CARVALHO, 1988; RAMOS, 2009; LORINI, et al. 2010).

Plodia interpunctella (Hubner, 1813) (Lepidoptera: Pyralidae) - traça dos cereais (figura 3 ) e danos causados (figura 4).

As traças dos cereais são mariposas com cerca de $20 \mathrm{~mm}$ de envergadura, cabeça e tórax de cor pardo-avermelhado, asas anteriores avermelhadas e acinzentadas, além de pontos escuros bem nítidos. O primeiro par de asas é bastante característico, permitindo diferenciar-se das demais traças $(\mathrm{ZUCHI}$ et al., 1993; GALLO et al., 2002; LORINI, 2002b). A cabeça apresenta um tufo de escamas em forma de chifres (TECNIGRAN, 2012). Os insetos adultos não se alimentam, possuem hábitos noturnos e o ciclo de vida de aproximadamente 28 dias (BIOCONTROLE, 2012; LORINI e SCHNEIDER, 1994).

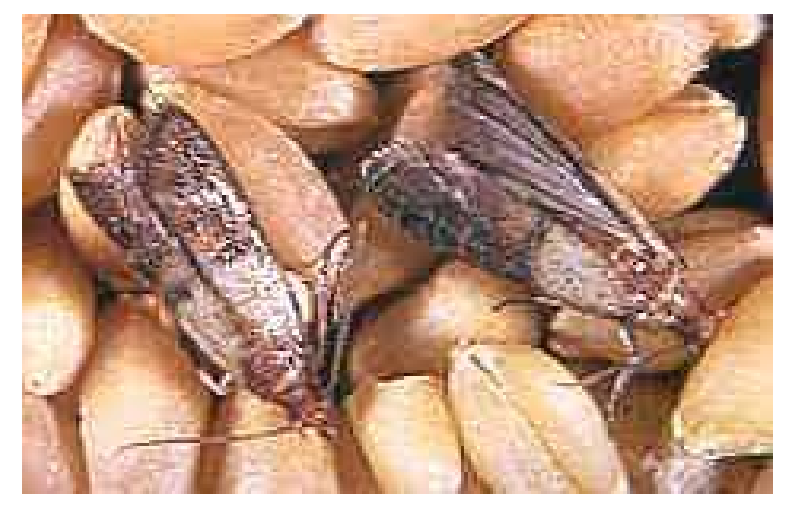

Figura 3. Adultos de Plodia interpunctella $(\mathrm{H}$.

Fonte: CSIRO

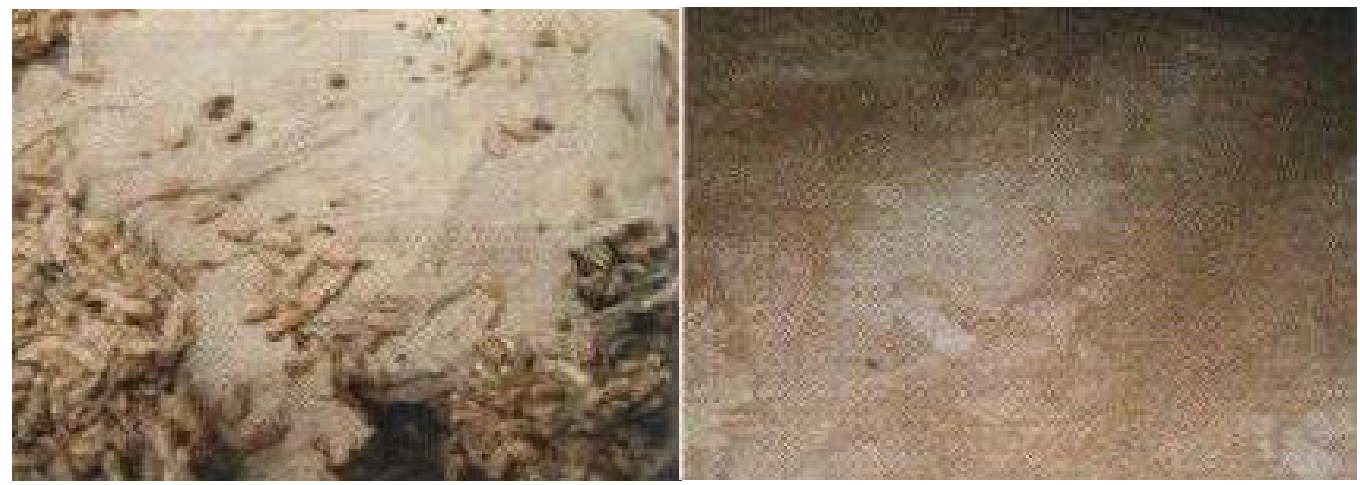

Figura 4 - Danos causados por P. interpunctella em ração. Fonte (Campos e Zorzenon 2006) 
As fêmeas colocam de 100 a 400 ovos, que são dispostos na superfície de grãos em grupos ou isolados. As larvas apresentam coloração branca e após o desenvolvimento ter sido completado passa a tonalidade rosada em algumas partes do corpo, tecem um casulo de seda, no interior do qual a larva se transforma em pupa nas frestas e fendas das paredes e bordas da sacaria (GALLO et al., 1988; GALLO et al., 2002; LORINI, 2002b) citados por (RAMOS, 2009). Podem atacar uma grande variedade de produtos farináceos, cacau, soja, arroz, milho, feijão, frutas secas e rações de animais (BORROR e DELONG, 1964).

Sitophilus oryzae (Linné, 1763) e Sitophilus. zeamais Motschulsky, 1885 (Coleoptera: Curculionidae) (figura 5) e (figura 6) - gorgulhos dos cereais, - Danos causados pelo $S$. zeamais em milho (figura 7) e Danos causados por S. oryzae em trigo e macarrão (figura 8).

Essas duas espécies são bastante semelhantes morfologicamente, a diferenciação ocorre na genitália interna (CAMPOS, 2005). O S. Zeamais tem uma distribuição generalizada e é a praga mais importante do milho (GALLO et al., 2002).

O inseto adulto mede de 2,0 a 3,5 mm de comprimento, apresenta coloração castanho-escuro, com quatro manchas avermelhadas nos élitros visíveis logo após a eclosão. Sua cabeça é deslocada para frente, na forma rostro recurvado, onde se localizam as peças bucais. Os machos apresentam rostro mais curto e grosso e as fêmeas longos e afilados. O protórax é fortemente pontuado e os élitros estriados (GALLO et al., 1970; GALLO et al., 1988; GALLO et al., 2002; LORINI, 2002b; LORINI, et al., 2010). 


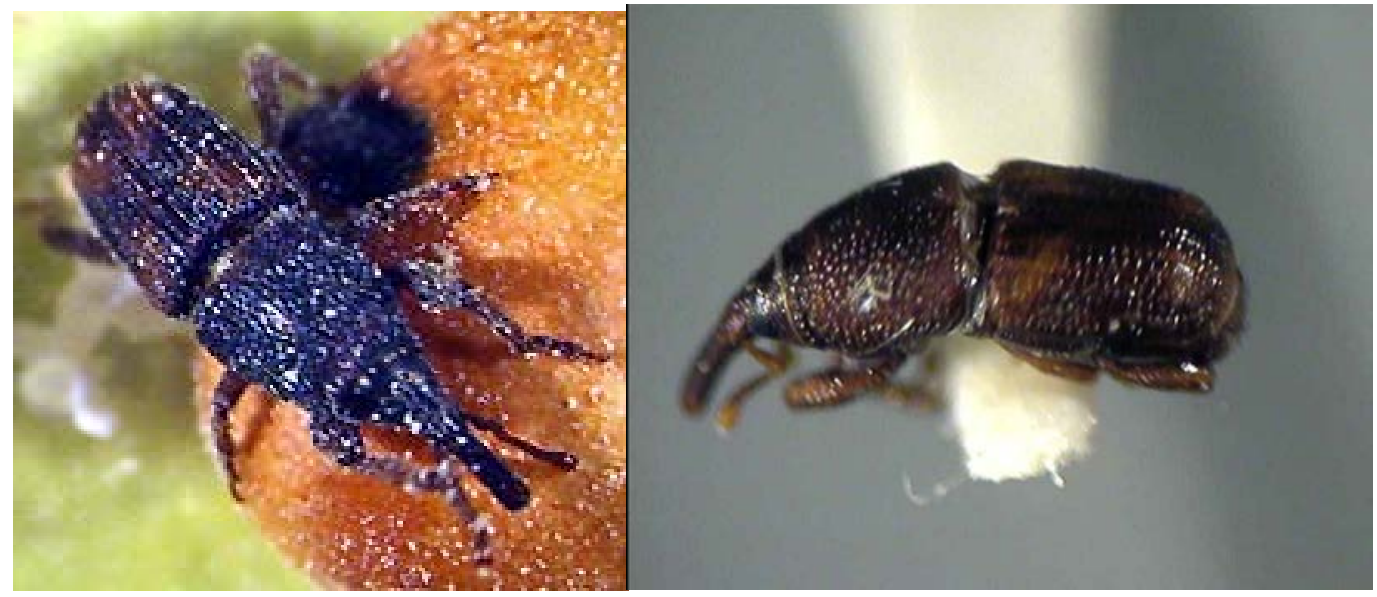

Figura 5. Sitophilus oryzae (L.)

Figura 6. Sitophilus. zeamais M

Fonte: http://www.amiciinsoliti.it/cibovivo/sitophilus.html Fonte: J.A. Jackman
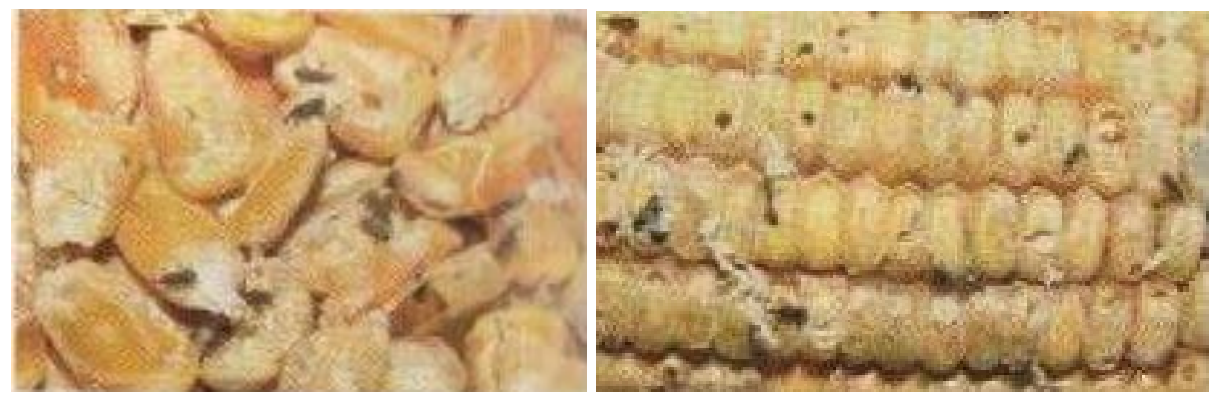

Figura 7 - Danos causados pelo S. zeamais em milho Fonte: Campos e Zorzenon (2006)
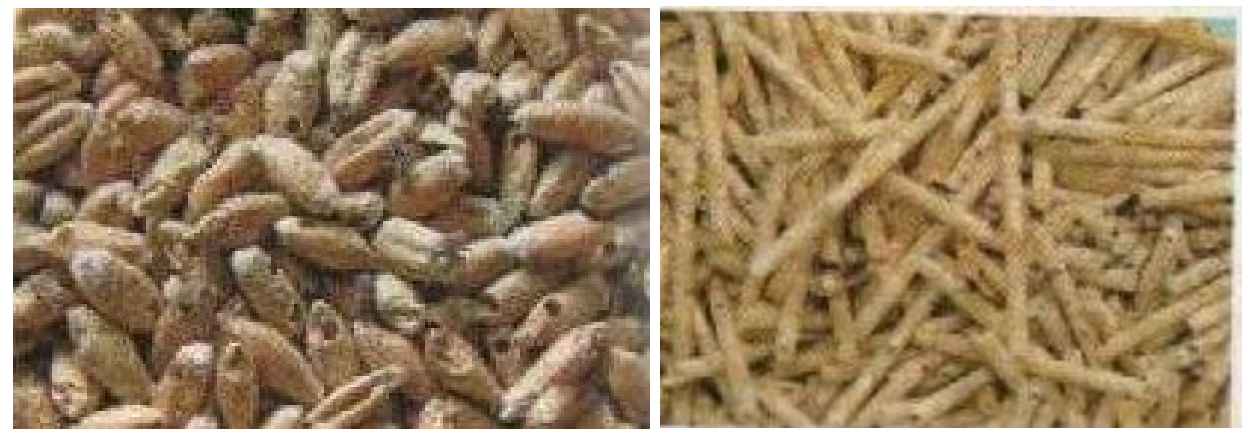

Figura 8 - Danos causados por S. oryzae em trigo e macarrão

Fonte: Campos e Zorzenon (2006)

A fêmea pode colocar entre 200 a 400 ovos, que são colocados nos grãos armazenados ou no campo pelos adultos. O período de incubação oscila entre 3 e 6 dias (GALLO et al., 2002; LORINI, 2001; LORINI, 2002b).

Segundo Kurtz e Harris (1962), as larvas são de coloração amarelo-claro com a cabeça mais escura, imóveis se desenvolvem no interior do grão. As pupas apresentam coloração branca e o ciclo evolutivo é de 4 a 5 meses. 
Possuem um elevado potencial de reprodução, podendo atacar um grande número de produtos como: trigo, milho, cevada, aveia, centeio, macarrão, biscoito, sorgo, arroz, etc, causando enormes prejuízos anualmente. Tanto a larva como a inseto adultos atacam os grãos inteiros, após as larvas se desenvolverem no grão, saem para transformarem pupas e posteriormente em adultos, os danos são redução de peso e na qualidade do grão (LORINI e SCHNEIDER, 1994 citado por (LORINI, 2002b), citados por (RAMOS, 2009).

Ambas as espécies podem ocorrer juntas no mesmo grão, independente do tipo de grão e são consideradas pragas primárias internas com grande importância, pois podem apresentar infestação cruzada, infestando os grãos tanto no campo como nos armazéns, onde penetram profundamente os grãos (GALLO et al., 1988; LORINI, 2002b).

\subsection{Métodos de Controle}

\subsubsection{Método químico}

Segundo Gallo et al., (2002) a capacidade de destruição das pragas de produtos armazenados é muito grande e devido a esse problema é recomendado que se faça o controle preventivo, pois devido as condições dos depósitos, qualquer população de insetos pragas dos grãos podem aumentar assustadoramente. Devido a esses problemas devem ser feitas três etapas obrigatórias de desinfestação dos armazéns. Aplicação residual consiste na pulverização do piso, teto, sacarias, paredes, com inseticidas para eliminar os insetos, que porventura permaneçam no interior dos armazéns após a última estocagem. Geralmente são utilizados os seguintes produtos: Sumigran CE ( $500 \mathrm{~g} / \mathrm{l})$ (feniltrotion) $-0,5 \mathrm{ml} / \mathrm{m}^{2}$ superfície, Actellic CE ( $500 \mathrm{~g} / \mathrm{l}$ ) (pirimifós-metílico) - 1 $\mathrm{ml} / \mathrm{m}^{2}$ superfície e K-Obiol ( $25 \mathrm{~g} / \mathrm{l}$ ) (deltametrina)$0,5 \mathrm{ml} / \mathrm{m}^{2}$ superfície. Aplicação de proteção consiste na aplicação de inseticidas misturados aos produtos, que serão armazenados a granel, ou diretamente sobre sacarias quando os grãos são ensacados, é realizada para proteger os produtos armazenados de reinfestações (GALLO et al., 2002). Os mais utilizados são os Sumigran CE ( $500 \mathrm{~g} / \mathrm{l})$ (feniltrotion) $-0,5 \mathrm{ml} / \mathrm{m}^{2}$ superfície, Actellic CE ( $500 \mathrm{~g} / \mathrm{l}$ ) 
(pirimifós-metílico)- $1 \mathrm{ml} / \mathrm{m}^{2}$ superfície, K-Obiol (25g/l) (deltametrina) - 0,5ml/m² superfície e K-obiol e (deltametrina) - 0,5 kg/ton. Na fumigação são utilizados produtos conhecidos como fumigantes, como é o caso, do brometo de metila e fosfina. O brometo de metila pode provocar a inibição da germinação das sementes e o seu objetivo é exterminar os insetos nas diferentes fases do ciclo evolutivo. São aplicados dentro de ambientes fechados e todos os produtos que são destinados ao armazenamento nos depósitos devem ser fumigados antes de armazenados (CELARO, 2002; GALLO et al., 2002), citados por (RAMOS, 2009).

Segundo Campos (2005) para a fumigação recomendam-se a utilização do fosfeto de alumínio ou de magnésio. São produtos que se apresentam nas formas sólidas e que em contato com o ar ambiente, liberam a fosfina, um gás inodoro, incolor e extremamente tóxico, porém seguro quando observadas as recomendações dos fabricantes. A dose recomendada para a utilização é de $2 \mathrm{~g}$ de fosfina (ingrediente ativo) por $\mathrm{m}^{3}$ de câmara e o tempo mínimo de exposição é 96 horas, e a câmara deverá permanecer fechada durante esse período de tratamento.

\subsubsection{Método físico}

São vários os métodos físicos de controle de insetos e a maioria deles basicamente estão relacionados com a alteração dos fatores ecológicos tais como: a temperatura e o teor de umidade relativa do ar e do grão durante o armazenamento. É de fundamental a utilização desses fatores como método de controle das pragas de produtos armazenados. Um dos métodos mais utilizados é a aeração, que força a passagem do ar através dos grãos, sendo fundamental tanto para reduzir e uniformizar a temperatura como para alcançar o teor de umidade adequado. É de extrema importância manter a estabilidade da umidade e da temperatura nos locais de armazenamento (SANTOS, 2002).

Outro processo utilizado é a aplicação das radiações ionizantes com objetivo de tornar os insetos estéreis, com o objetivo de controlar e erradicar as populações de pragas. Este método é relativamente novo, todavia, a esterilização dos insetos utilizando radiações ionizantes, foi constatada, desde 1916 por RUNNER. Como a radiação gama é extremamente penetrante, enquanto os raios $X$ são menos 
penetrantes e possui um baixo rendimento em sua produção, pois somente de 3 a $5 \%$ da energia aplicada é efetivamente convertida em raios X (JUNIOR et al, 2002; CENA, 2012).

Segundo Hallman (2013) a utilização da irradiação visando a desinfestação de produtos armazenados atacados pelos insetos pragas está aumentando rapidamente e são vários países que já utilizam desta tecnologia. Afirma que para prevenir a reprodução de pragas de produtos armazenados as doses de radiação podem variar de 0.05 kGy para coleópteros e de 0.45 kGy para lepidópteros.

Segundo Mello (2000) as formas de radiação utilizadas no processo de irradiação de alimentos provocam ionização, ou seja, criam cargas positivas ou negativas. A formação dessas cargas resulta em efeitos químicos e biológicos que impedem a divisão celular em bactérias pela ruptura de sua estrutura molecular. Os níveis utilizados de energia não são suficientes para induzir radioatividade nos alimentos. O alimento, em hipótese alguma, entra em contato com a fonte de radiação.

O Comitê da junta de especialistas sobre irradiação de alimentos formados pelos órgãos das Nações Unidas: Food and Agriculture Organization (FAO), Agência Internacional de Energia Atômica (AIEA), Organização Mundial da Saúde (OMS) e o Codex Geral de Padrões para Alimentos Irradiados recomendam os seguintes tipos de radiação ionizante, considerados adequados para irradiação de alimentos (DIEHL, 1990; IAEA, 1982): Radiação gama originados de ${ }^{60}$ Co e ${ }^{137} \mathrm{Cs}$, Raios-X com energias de até $5 \mathrm{MeV}$ e Elétrons com energias de até $10 \mathrm{MeV}$.

Segundo a Internacional Consultative Group on Food Irradiation (ICGF) o uso apenas da irradiação como técnica na preservação de alimentos não resolve os problemas existentes na pós-colheita, mas pode ter um papel importante na redução dos prejuízos e do uso de agroquímicos. Sendo assim, a irradiação de alimentos pode ser empregada para inibir o brotamento de tubérculos e raízes, retardo do amadurecimento e deterioração de frutas e da senescência de flores, desinfestação (insetos), desinfecção (patógenos) e esterilização de embalagens. Em tecnologia de alimentos se preconiza a consonância de técnicas para preservação de alimentos e 
a irradiação é um processo que pode ser empregado isolada e/ ou conjuntamente com outras tecnologias, tais como resfriamento, aquecimento, congelamento e embalagem (WIENDL, 1997), citado por (JUNIOR et al., 2002).

A dose de radiação é medida em Grays (Gy) ou quilograys (kGy), onde 1 Gray $=0,001$ kGy $=1$ joule de energia absorvida por quilograma de alimento irradiado. Para inibir o brotamento de raízes e tubérculos, por exemplo, a dose necessária varia entre 0,05 a 0,15 kGy, já para retardar o amadurecimento de frutas, é necessário a dose 1 kGy. Para prevenir e desinfestar produtos armazenados como grãos, a dose 0,1 a 2 kGy são suficientes (CENA, 2012).

A Organização Mundial da Saúde (OMS) considera que alimentos irradiados com doses até 10 kGy não necessitam de avaliação toxicológica ou nutricional.

Mello (2000) afirmou que o processo de irradiação dos alimentos é bastante seguro para o meio ambiente, pois não produz nenhum tipo de resíduo. Nesse processo, os equipamentos mais utilizados são os irradiadores de Cobalto-60. Esses equipamentos consistem numa fonte de Cobalto-60 instalados em uma câmara de irradiação cujas paredes são blindadas de concreto. Quando não utilizada essa fonte fica armazenada numa piscina (poço) com água tratada, revestida de aço inox, no interior da blindagem (CENA, 2012).

Segundo o Centro de Energia Nuclear da Universidade de São Paulo CENA/USP (2012) o processo de irradiação acarreta poucas alterações químicas nos alimentos e nenhuma delas é perigosa para a saúde. Nos últimos 35 anos, inúmeras pesquisas científicas foram realizadas para detectar e isolar produtos formados pela irradiação e não foi detectada nenhuma substância que seja produzida exclusivamente nos alimentos irradiados.

Raios gamas é um tipo de radiação eletromagnética que resulta de uma redistribuição das cargas elétricas em um núcleo. Um raio gama é um fóton de alta energia emitido pelo núcleo de alguns átomos. A única coisa que distingue um raio gama dos fótons de luz visível emitidos por uma lâmpada é o comprimento de onda. O comprimento de onda de um raio gama é centenas de milhares de vezes menores 
que o da luz visível, e, portanto a freqüência é centenas de milhares de vezes maiores. A radiação gama é extremamente penetrante (JUNIOR et al., 2002; ABC DA FISICA NUCLEAR, 2012).

A radiação gama é utilizada em escala comercial há mais de 40 anos e hoje conta com mais de 150 plantas operacionais no mundo, e tem uma larga escala de utilização na indústria, como: esterilização de materiais médico-cirúrgico, laboratório, frascos, embalagens, desinfestação e conservação de alimentos armazenados, descontaminação de produtos, coloração de vidros e outras finalidades (EMBRARAD, 2012).

A irradiação de alimentos é baseada na absorção da energia da radiação gama, que consiste em uma radiação com a mesma característica física da luz visível, das ondas de rádio, de TV e, a quantidade de energia absorvida pode ser facilmente controlada de modo a se obter o efeito desejado. A interação da radiação se processa em nível molecular (MELLO, 2000).

A irradiação deve ser aplicada em alimentos já embalados, porem não evita a recontaminação ou a reinfestação. A qualidade do alimento irradiado, bem como o de outro alimento, é função da qualidade do produto original, que deverá ser produzido segundo as boas praticas de fabricação (FARKAS, 1985; VILLAVICENCIO, 1998).

A adequação nutricional dos alimentos irradiados é sumarizada em muitas revisões, as quais mostram claramente que as alterações ocorridas nos alimentos são mínimas ou mesmo em alguns casos, nulas quando se é respeitada a dose certa para cada tipo de alimento (DIEHL e JOSEPHSON, 1994; DIEHL, 1995). Segundo (DIEHL, 1992; DIEHL, 1995) nas doses de até 1 kGy, as perdas nutricionais são consideradas insignificantes e nenhuma das alterações conhecidas encontradas nos alimentos é nociva ou perigosa, estando dentro dos limites encontrados normalmente para os alimentos (SATIN, 1993; DELINCÉE et. al., 1998). 


\subsubsection{Método por comportamento}

Consiste na utilização de armadilhas de feromônio para realização de monitoramento e controle dos insetos. O feromônio é um agente biológico produzido pelos insetos da mesma espécie, que sintetizado e utilizado para comunicação entre eles. Este método já é amplamente utilizado em outros países e recentemente no Brasil. As armadilhas são utilizadas para atraírem os insetos e apresentam-se de várias formas e, são específicas para cada tipo de inseto, portanto é necessária sempre que possível uma orientação técnica. O uso das armadilhas de feromônio deve ser racionalizado dentro do conhecimento prévio dos locais considerados potenciais para o ataque dos insetos (GITZ et al., 2002; RAMOS, 2009). Segundo Gallo et. al., (2002) esta técnica permite definir a melhor época para o controle de pragas.

\subsubsection{Embalagem}

São utilizadas para manter a qualidade dos alimentos comercializados, para isso há a necessidade de se usar métodos adequados de manipulação, pré, póstratamento e um armazenamento correto e ideal, para que os produtos não se deteriorem. Geralmente nos armazéns os insetos conseguem perfurar e penetrar nas embalagens vulneráveis. No seu interior eles colocam os seus ovos sobre o produto, e se desenvolvem rapidamente, por essa razão, é que as embalagens dos alimentos devem apresentar certa resistência, portanto ela desempenha um papel fundamental, impedindo o contato e a proliferação de pragas no produto acondicionado. Além de conter o produto, a embalagem é muito importante na conservação do alimento, mantendo qualidade e a segurança, atuando como barreira contra fatores responsáveis pela deterioração química, física e microbiológica dos produtos.

Segundo a RDC 259 (de 20/09/2002) da ANVISA embalagens são definidas como recipiente, pacote ou a embalagem pode ser destinada para garantir a conservação, facilitar o transporte e manuseio dos alimentos. Embalagens são 
classificadas em: primária ou envoltório primário são embalagens que entram em contato direto com os alimentos. Embalagens secundárias ou pacote são destinados a conter as embalagens primárias já as embalagens terciárias são destinadas a conter uma ou várias embalagens secundárias.

Segundo Moura e Banzato (2003) afirmaram que de um modo geral as embalagens são consideradas essenciais e imprescindíveis para a sociedade moderna, sem sombra de dúvida é uma necessidade tão antiga quanto a própria história do homem. Que em tempos muito remotos, pedaços de árvore, chifres, peles e bexigas de animais eram usados pelos primitivos para acondicionar alimentos. Portanto a embalagem de produtos alimentícios ocupa um papel central na indústria moderna de alimentos e tem originado importantes avanços tecnológicos que demonstram cada vez mais um caráter interdisciplinar.

Há mais de 10.000 anos surgiram as primeiras embalagens que serviam como simples recipientes para beber ou estocar alimentos. Os primeiros recipientes, nada mais eram do que as cascas de coco ou conchas do mar, eram usadas em estado natural, sem qualquer beneficiamento, passaram com o tempo a ser obtidos a partir da habilidade manual do homem. A primeira matéria-prima usada em maior escala para a produção de embalagens foi o vidro. Embora o uso de metais como cobre, ferro e estanho, tenha surgido na mesma época que a cerâmica de barro, foi somente nos tempos modernos que eles começaram a ter um papel importante para a produção de embalagem (CAVALCANTI e CHAGAS, 2006), citado por (ALVES, 2011).

Posteriormente, surgiram inúmeras inovações na produção de embalagens. E os objetivos dessas novas embalagens eram permitir que os produtos alimentares fossem transferidos dos locais de produção para os centros consumidores, mantendo-se estáveis por longos períodos de estocagem. As embalagens de papel e papelão atenderam a esses requisitos. Elas podiam conter quantidades previamente pesadas de vários tipos de produtos, eram fáceis de estocar, 
transportar e empilhar, além de higiênicas (CAVALCANTI e CHAGAS, 2006), citado por (ALVES, 2011).

Foi somente pós-guerra mundial que ocorreu o aparecimento de um novo material para embalagens, o plástico. As resinas plásticas, como polietileno, poliéster, etc., ampliaram o uso dos invólucros transparentes, iniciado na década de 20 com o celofane, permitindo a oferta de embalagens numa infinidade de formatos e tamanhos (CAVALCANTI e CHAGAS, , 2006), citado por (ALVES, 2011).

O plástico chegou ao continente europeu na forma do náilon (poliamida) dos pára-quedas, na Segunda Guerra Mundial. Eram usados pelas tropas libertadoras norte-americanas e também pelos alemães. Na realidade, a Alemanha e os Estados Unidos disputaram a primazia no desenvolvimento dos plásticos. O polietileno já era utilizado para isolar cabos telefônicos e cabos submarinos, mas foi depois da Segunda Guerra Mundial que passou a ser amplamente empregado para embalagem de produtos alimentícios (CAVALCANTI e CHAGAS, 2006), citado por (ALVES, 2011).

O celofane, por sua vez, foi sendo substituído por materiais mais resistentes, como o polietileno e o BOPP (polipropileno biorientado, ou orientado em dois sentidos, vertical e transversal). Hoje, o celofane, desapareceu do mundo da embalagem (CAVALCANTI e CHAGAS, 2006), citado por (ALVES, 2011).

Ao chegar ao Brasil na década de 1950, o plástico encontrou certa resistência. A matéria plástica (termo que se usava) era vista como produto do capitalismo entre políticos de esquerda, intelectuais e estudantes secundaristas e universitários. No final da década de 1960, a Union Carbide, em Cubatão, foi a primeira fábrica de polietileno no Brasil, com capacidade de produzir 10 mil toneladas por ano. (CAVALCANTI e CHAGAS, 2006), citado por (ALVES, 2011). 
Com relação ao polietileno é de fácil moldagem, porém com baixo grau de transparência. Posteriormente ganhou transparência com PVC (Policloreto de Vinilo) e o PET (Politereftalato de etileno) com mais rigidez. O PET viria a ser tornar amplamente conhecido ao ser escolhido para as embalagens de refrigerantes. Não demorou até que o polipropileno passasse a ser amplamente consumido no mundo. No início, teve forte participação no segmento de tampas e nos sacos industriais para fertilizantes. Mais tarde, espalhou-se por todos os segmentos. É largamente utilizado na indústria alimentícia e também na área dos líquidos, cosméticos, desinfetantes, água mineral. Atualmente é a resina que tem as maiores taxas de aumento de produção (CAVALCANTI e CHAGAS, 2006), citado por (ALVES, 2011).

Na última década, o (PP) Polipropileno cresceu acima de 12\% ao ano. Isso aconteceu não só no Brasil, mas no mundo inteiro. Sua versão mais recente é o BOPP. Dos anos 70 até os dias atuais, a indústria brasileira de embalagem vem acompanhando as tendências mundiais produzindo embalagens com características especiais como o uso em fornos de microondas, tampas removíveis manualmente, proteção contra luz e calor e evidência de violação (CAVALCANTI e CHAGAS, 2006), citado por (ALVES, 2011).

A história da embalagem está aí, com milhares de transformações e evoluções ocorridas desde o início dos tempos, quando os primeiros homens e mulheres descobriram a necessidade de transportar e proteger mercadorias. Num contexto moderno, a embalagem é definida como uma função técnica-econômica que visa proteger e distribuir produtos ao menor custo possível, além de aumentar as vendas e, consequentemente, os lucros. O aspecto de proteção é, portanto, imprescindível em diferentes fases da produção e vida de um produto e tem como alvo final um consumidor cada vez mais consciente e exigente (MESTRINER, 2005), citado por (ALVES, 2011).

O consumidor busca, cada vez mais, alimentos frescos e de boa qualidade, saudáveis, nutritivos, saborosos, com conveniência e facilidade de uso. De maneira a continuarem competitivos dentro deste segmento, os integrantes da Indústria 
Alimentícia não têm medido esforços na tentativa de agregar ao produto características que sejam simultaneamente mais econômicas e com maior segurança, ausência de conservantes e aditivos e maior vida útil, entre outros. A fim de atender esse novo consumidor, aumentar a produtividade e eliminar ineficiências dentro do sistema produtivo e de distribuição, a palavra de ordem na indústria de alimentos e do setor de embalagens atual é alinhar-se as novas tecnologias e tendências (MADI, 2000), citado por (ALVES, 2011).

Hoje em dia, a indústria usa mais de 30 diferentes tipos de filme, destes, os mais utilizados em alimentos são: o polietileno, polipropileno e poliéster. Existe também um aumento na utilização de filmes multicamada que muitas vezes combinam plásticos com outros tipos de materiais, como alumínio e papel, a fim de alcançar benefício específico conferido por cada tipo de material (RIUDAVETS et al., 2007), citado por (ALVES, 2011).

Segundo O' Donnell e Sangster (1970) os principais problemas das embalagens são os efeitos causados pela ação da radiação ionizante que induzem mudanças químicas nos polímeros e as principais são: cisão e reticulação simultâneas nas cadeias poliméricas e o seu efeito na rede cristalina, que determinam as mudanças nas propriedades do polímero e a formação de gases que são produtos da radiólise de massa molar baixa formação de ligações insaturadas.

Segundo Platzer (1967) concluiu que as mudanças induzidas pelas radiações ionizantes nos polímeros estão diretamente relacionadas com as estruturas químicas dos polímeros, aditivos usados na composição da resina, histórico do processamento da resina, e condições específicas da irradiação, isto é, dose absorvida, atmosfera de irradiação e, em certos casos, a taxa de dose.

As mudanças causadas pela radiação ionizante são de suma importância para as embalagens de alimentos porque podem afetar diretamente a qualidade dos gêneros alimentícios irradiados. A ação da radiação pode, por exemplo, alterar as 
propriedades de barreira (permeabilidade) das embalagens e propiciar a liberação de contaminantes, os quais podem migrar para o alimento acondicionado (CLOUGH et al., 1996).

Segundo Moura et al., (2004), concluíram que no processo de irradiação alguns produtos são formados como os monômeros e oligômeros residuais, que podem ser provenientes do processamento químico da resina ou pela radiação ionizante e dependendo da dose, podem migrar para os alimentos, podendo afetar as suas propriedades sensoriais e a segurança dos alimentos pré-embalados, resultando em riscos toxicológicos e sensoriais que devem ser avaliados antes que essas embalagens sejam utilizadas para os alimentos.

De um modo geral, quando se faz o tratamento com radiação ionizante de alimentos pré-embalados, pode haver a ocorrência de odor e sabor estranhos nos produtos, proveniente dos produtos voláteis gerados pela degradação da resina, dos resíduos de monômeros e oligômeros, dos aditivos que são incorporados nas embalagens e dos compostos produzidos pela radiólise causado pelo processo de irradiação (BUCHALLA, BOESS e BÖGL 1993).

Sen e Basfar (1998) concluíram que os efeitos imediatos da radiação ionizante sobre as propriedades ópticas dos materiais de embalagens são a mudança de cor e a modificação das suas características originais de barreira à luz. A radiação ionizante também pode induzir a formação de centro de cores permanentes e não permanentes nos materiais poliméricos, dependendo da dose de radiação aplicada.

Glough et al., (1996) afirmaram que quando o processo de irradiação ocorre na presença de ar, o oxigênio presente pode reagir com os radicais livres da matriz polimérica, podendo formar centro de cores, que desaparecem posteriormente em razão da ocorrência das reações de terminação radical-radical. Já os centros de cores permanentes correspondem à formação de cromóforos conjugados, estáveis 
dentro da matriz polimérica, enquanto os centros de cores não permanentes estão associados à presença de radicais livres presos na matriz.

De uma forma geral os materiais plásticos utilizados para embalar alimentos devem apresentar resistência físico-química para suportar os efeitos causados pelas radiações ionizantes, e não devem sofrer redução nas suas características de proteção, nem transferir substâncias tóxicas ou causar odores e sabores estranhos ao produto acondicionado (BUCHALLA et al., 1999).

Os plásticos são os materiais de embalagens mais estudados e usados nos alimentos tratados por radiação, principalmente os termoplásticos, em forma de filmes ou laminados, que podem ter como substrato papel, alumínio ou cartão. São praticamente os mesmos materiais utilizados nos processos tradicionais de conservação, embora sejam relevantes as seguintes considerações: como consequência da irradiação, as embalagens são passíveis de alterações químicas e físicas, causadas, geralmente, pela reticulação e degradação, podendo ocorrer desprendimento de gases e substâncias capazes de afetar as características dos alimentos embalados (WHO, 1999).

Os efeitos da radiação nos materiais para embalagens flexíveis para utilização de alimentos e a sua adequação aos processos industriais de irradiação foi o objetivo de estudos, desde a década de 70, nos Estados Unidos, Canadá, França e Reino Unido, e também em outros paaíses. Baseados nestas pesquisas foram aprovados vários materiais para serem usados como embalagens de alimentos, nos processos de radioesterilização e de pasteurização por irradiação (WHO, 1999).

Moura (2006) estudou os efeitos das radiações ionizantes em alguns tipos de embalagens de polietileno e após a irradiação foram feitas avaliações por um período de até 3 meses. Pelos resultados obtidos concluiu que os filmes estudados podem ser esterilizados sob o ponto de vista das propriedades avaliadas como 
embalagens para produtos pasteurizados por irradiação e radioesterilizáveis por irradiadores gama ou aceleradores de elétrons com doses de até 30 kGy.

Segundo Modolo et al., (2009) concluíram que as embalagens com furos para facilitar as troca gasosas utilizadas para arroz, apresentaram maior facilidade para a penetração de Sitophilus oryzae em relação as embalagens não furadas. Já a dose de 1 kGy foi suficiente para induzir a desinfestação do arroz.

Alves (2011) observou que em relação à resistência de perfuração por $L$. serricorne, $P$. interpunctella e $S$. zeamais, as estruturas poliméricas avaliadas apresentaram baixa resistência à perfuração por insetos antes e após o tratamento. BOPPmet/BOPP $(50 \mu \mathrm{m})$, PETmet/BOPP $(32 \mu \mathrm{m})$, PET/PP1 $(72 \mu \mathrm{m})$ e PET/PP2 $(32 \mu \mathrm{m})$ apresentaram mudanças, perdas significativas nas estruturas $(p<0.05)$ e nas propriedades mecânicas estudadas. BOPP/PP $(50 \mu \mathrm{m})$ apresentaram o melhor conjunto de respostas nas propriedades mecânicas ao tratamento por radiação com feixe de elétrons em doses de até 10 kGy. Dentre as propriedades mecânicas avaliadas a selagem foi a mais afetada pela radiação ionizante, pois apresentou perdas crescentes com o aumento das doses de radiação aplicadas. 


\section{MATERIAIS E MÉTODOS}

O trabalho foi desenvolvido no Laboratório de Radiobiologia e Ambiente do Centro de Energia Nuclear na Agricultura - CENA/USP, a irradiação das amostras foi realizada em uma fonte de Cobalto-60, tipo Gammacell-220, sob uma taxa de dose de 0,456 kGy/hora.

Foram utilizados neste trabalho insetos das espécies: Lasioderma serricorne, Plodia interpunctella, Sitophilus zeamais e Sitophilus oryzae do Laboratório de Radiobiologia e Ambiente, onde são criados as várias gerações nos seguintes substratos: L. serricorne em farinha de trigo mais levedura de cerveja, $P$. interpuntella em fubá, farinha de trigo, farelo de arroz e germe de trigo, S. zeamais em milho e S. oryzae em arroz. Estes insetos são mantidos em sala climatizada com temperatura de $27 \pm 2^{\circ} \mathrm{C}$ e umidade relativa de $70 \pm 5 \%$.

No primeiro ensaio foram utilizadas embalagens de amostras grátis medindo em media $10 \mathrm{~cm} \times 20 \mathrm{~cm}$ com capacidade de aproximadamente 70 gramas de substratos (ração) com 4 tipos de marcas existentes no comercio: (1), (2), (3) e (4). Cada tratamento constou de 10 repetições, que foram irradiadas com as doses de: 0 (controle) 0,5; 1,0 e 2,0 kGy, para se fazer a desinfestação das amostras. Após a irradiação (desinfestação) todas as embalagens irradiadas e a testemunha foram acondicionadas em caixas plásticas de $80 \mathrm{~cm}$ x $50 \mathrm{~cm}$ com tampa, onde foram liberados os insetos num total de 400 de cada espécie de inseto para cada caixa, numa proporção de 10 insetos para cada embalagem (repetição) e foram mantidas em sala climatizada com $27 \pm 2^{\circ} \mathrm{C}$ e umidade relativa de $70 \pm 5 \%$. Essa metodologia foi feita para se avaliar a penetração dos insetos no interior das embalagens, para as quatro espécies de insetos, $L$. serricorne, $P$. interpuctella, S. zeamais e S. oryzae. As avaliações das embalagens foram feitas 60 dias após a liberação dos insetos nas caixas. Foi observado o numero de furos nas embalagens e o numero de insetos no interior de cada repetição (embalagem) dentro dos tratamentos.

No segundo ensaio foram utilizadas embalagens confeccionadas de acordo com a metodologia de (Arthur e Arthur, 2003; Arthur e Arthur 2004), com todos os materiais utilizados nas embalagens do primeiro ensaio. Cada embalagem foi feita 
com uma seladora de plástico com o tamanho de $10 \mathrm{~cm} \times 15 \mathrm{~cm}$, com capacidade de 30 gramas de substratos (ração) por saquinho para todas as marcas comerciais utilizadas. Para cada marca de ração, cada tratamento constou de 10 repetições, sendo que em cada repetição foram inoculados 10 insetos de cada espécie, num total de 400 insetos por ensaio. As repetições, ou seja, as embalagens com substrato e inseto no seu interior foram vedadas em seladora comercial, e posteriormente irradiadas com as doses de: 0 (controle) 0,5; 1,0 e 2,0 kGy,. Após a irradiação, todas as embalagens irradiadas e mais a testemunha foram mantidas em sala climatizada com $27 \pm 2^{\circ} \mathrm{C}$ e umidade relativa de $70 \pm 5 \%$. Isso foi realizado também para as quatro espécies de insetos: $L$. serricorne, $P$. interpuctella e $S$. zeamais e S. oryzae. Após 60 dias da irradiação foram feitas contagens dos insetos no interior de cada embalagem, números de furos nas embalagens, em cada tratamento, determinando-se então as doses letais para cada espécie de inseto. $O$ delineamento estatístico experimental para o primeiro e segundo ensaio foram inteiramente casualizado em esquema de 4x1 (4 tratamentos e 1 época de amostragem) e 10 repetições. Os resultados obtidos das avaliações foram submetidos a analise de variância pelo Test $F$, e a comparação das medias pelo Teste de Tukey a 5\%, utilizando-se o sistema estatístico SAS (STATISTICAL ANALYSIS SISTEM, 1989). 


\section{RESULTADOS E DISCUSSÕES}

Constam nas Tabelas 1, 2, 3 e 4, os resultados dos ensaios com as rações dos tipos 1, 2, 3 e 4, nos tratamentos controles e irradiados com doses crescentes de radiação gama do Cobalto-60: 0 (controle); 0,5; 1,0 e 2,0 kGy, e submetidas à infestação forçada com as quatro espécies de insetos. As avaliações foram realizadas após 60 dias da infestação, para que houvesse tempo suficiente para o desenvolvimento completo do ciclo evolutivo dos insetos. Para elucidar melhor esses resultados construíram-se as Figuras 9, 10, 11 e 12, onde podemos observar que para todas as espécies houve uma variação no numero médio de insetos e furos para todos os tratamentos na ração tipo 4 .

Pelos resultados dessas tabelas, podemos observar que a embalagem da ração numero 4 foi a única que apresentou diferença significativa entre os tratamentos, quando se avaliou o numero de insetos e de furos nas embalagens. Essa diferença numérica foi diferente para cada espécie de inseto, provavelmente este fato esteja diretamente relacionado com a proporção de insetos machos e fêmeas liberadas nas caixas utilizadas para cada ensaio de infestação forçada. Podemos observar também que não houve relação proporcional entre esses dois parâmetros avaliados e as doses de radiações utilizadas. Todas as demais marcas de embalagem não apresentaram diferença significativa em nível de $5 \%$, pois nenhum dos parâmetros avaliados foi observado nessas embalagens, ou seja numero de insetos e furos, portanto todas foram resistentes ao ataque das espécies de: Sitophilus zeamais, Sitophilus oryzae, Lasioderma serricorne e Plodia interpuctella, estando esses resultados semelhantes aos de (RAMOS, 2009; MODOLO et. al., 2009; ALVES 2011; FOLLETT, et al., 2013; HALLMAN, 2013).

Com relação ás doses de radiação gama aplicadas nas amostras de rações a menor foi 0,1 kGy maior que a recomendada pela AIEA para o tratamento quarentenário de pragas. Como não foi obervado insetos e furos, também nas amostras controle, podemos afirmar que o processamento das rações 1, 2 e 3, foi suficiente para eliminar as infestações oriundas dos subprodutos (de soja, trigo e milho). Já para a ração numero 4 , esse resultado não foi possível de ser observado. 
Tabela 1. Numero médio de furos e emergência media de adultos de Sitophilus zeamais, provenientes das amostras de rações irradiadas com doses crescentes de radiação gama do Cobalto-60 e submetidas a infestação forçada.

\begin{tabular}{|c|c|c|c|c|c|c|c|c|}
\hline Doses/kGy & $\begin{array}{r}\text { Raç } \\
\text { Inseto }\end{array}$ & $\begin{array}{l}1 \\
\text { Furos }\end{array}$ & $\begin{array}{r}\text { Raçá } \\
\text { Insetos }\end{array}$ & $\begin{array}{l}22 \\
\text { Furos }\end{array}$ & $\begin{array}{l}\text { Raçãc } \\
\text { Insetos }\end{array}$ & $\begin{array}{l}3 \\
\text { Furos }\end{array}$ & $\begin{array}{r}\text { Raçãc } \\
\text { Insetos }\end{array}$ & $\begin{array}{l}4 \\
\text { Furos }\end{array}$ \\
\hline 0 (controle) & $0,0 a$ & $0,0 a$ & $0,0 a$ & $0,0 a$ & $0,0 a$ & $0,0 a$ & $25,0 c$ & $10,0 \mathrm{c}$ \\
\hline 0,5 & $0,0 a$ & $0,0 a$ & $0,0 a$ & $0,0 a$ & $0,0 \mathrm{a}$ & $0,0 a$ & $29,0 b$ & $13,0 b$ \\
\hline 1,0 & $0,0 a$ & $0,0 a$ & $0,0 a$ & $0,0 a$ & $0,0 a$ & $0,0 a$ & $36,0 a$ & $15,0 a$ \\
\hline 2,0 & $0,0 a$ & $0,0 a$ & $0,0 a$ & $0,0 a$ & $0,0 a$ & $0,0 a$ & $19,0 d$ & $9,0 d$ \\
\hline
\end{tabular}

Médias seguidas com as mesmas letras não diferem entre si a $5 \%$ de probabilidade pelo teste de Tukey

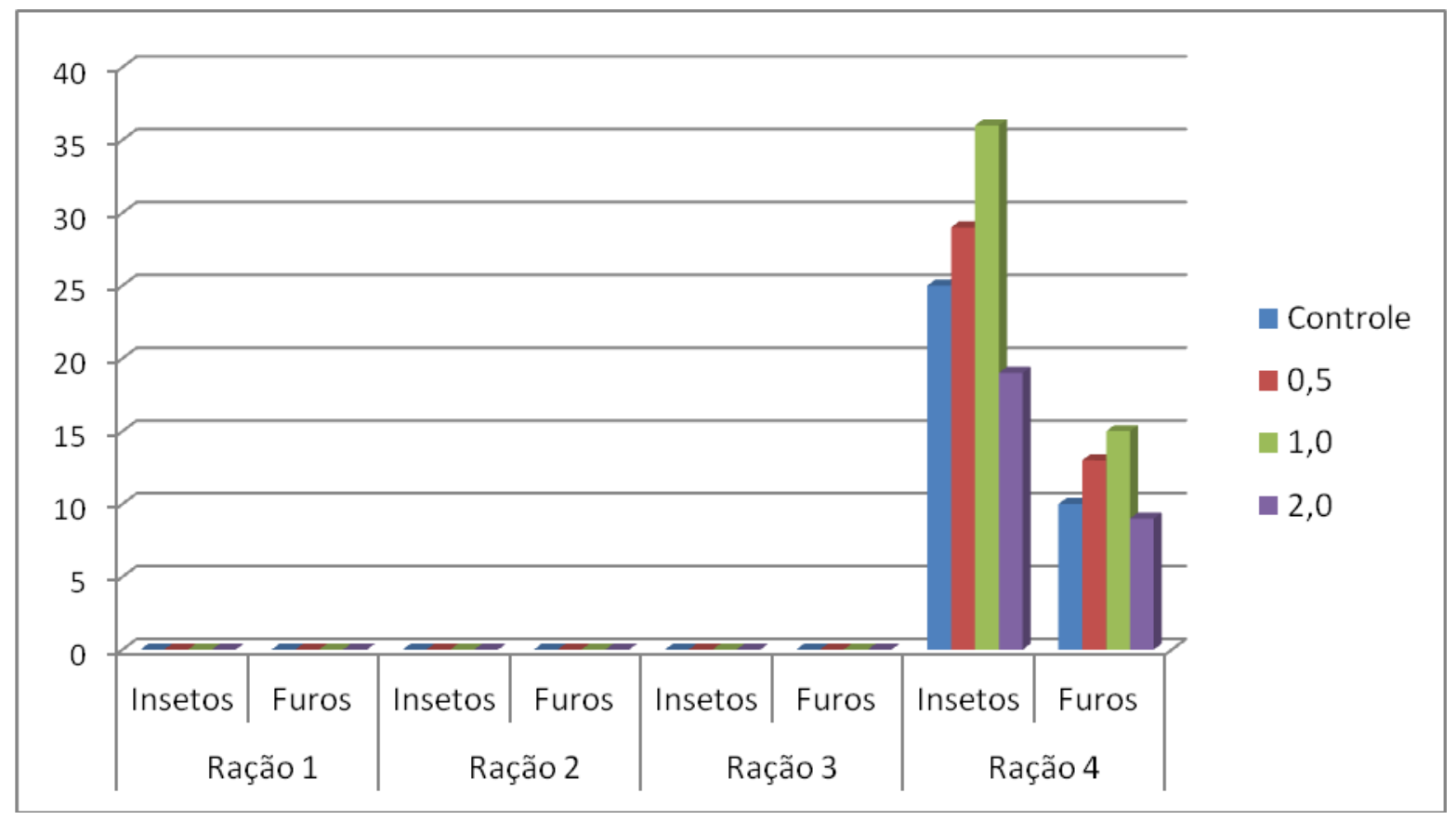

Figura 9. Numero médio de furos e emergência media de adultos de Sitophilus zeamais, provenientes das amostras de rações irradiadas com doses crescentes de radiação gama do Cobalto-60 e submetidas a infestação forçada. 
Tabela 2. Numero médio de furos e emergência media de adultos de Sitophilus oryzae, provenientes das amostras de rações irradiadas com doses crescentes de radiação gama do Cobalto-60 e submetidas a infestação forçada.

\begin{tabular}{|l|cc|cc|cc|cc|}
\hline Doses/kGy & \multicolumn{2}{|c|}{ Ração 1 } & \multicolumn{2}{c|}{ Ração 2 } & \multicolumn{2}{c|}{ Ração 3 } & \multicolumn{2}{c|}{ Ração 4 } \\
& Insetos & Furos & Insetos & Furos & Insetos & Furos & Insetos & Furos \\
\hline 0 (controle) & $0,0 \mathrm{a}$ & $0,0 \mathrm{a}$ & $0,0 \mathrm{a}$ & $0,0 \mathrm{a}$ & $0,0 \mathrm{a}$ & $0,0 \mathrm{a}$ & $27,0 \mathrm{~b}$ & $12,0 \mathrm{c}$ \\
\hline 0,5 & $0,0 \mathrm{a}$ & $0,0 \mathrm{a}$ & $0,0 \mathrm{a}$ & $0,0 \mathrm{a}$ & $0,0 \mathrm{a}$ & $0,0 \mathrm{a}$ & $30,0 \mathrm{a}$ & $15,0 \mathrm{~b}$ \\
\hline 1,0 & $0,0 \mathrm{a}$ & $0,0 \mathrm{a}$ & $0,0 \mathrm{a}$ & $0,0 \mathrm{a}$ & $0,0 \mathrm{a}$ & $0,0 \mathrm{a}$ & $21,0 \mathrm{c}$ & $10,0 \mathrm{~d}$ \\
\hline 2,0 & $0,0 \mathrm{a}$ & $0,0 \mathrm{a}$ & $0,0 \mathrm{a}$ & $0,0 \mathrm{a}$ & $0,0 \mathrm{a}$ & $0,0 \mathrm{a}$ & $15,0 \mathrm{~d}$ & $17,0 \mathrm{a}$ \\
\hline
\end{tabular}

Médias seguidas com as mesmas letras não diferem entre si a $5 \%$ de probabilidade pelo teste de Tukey

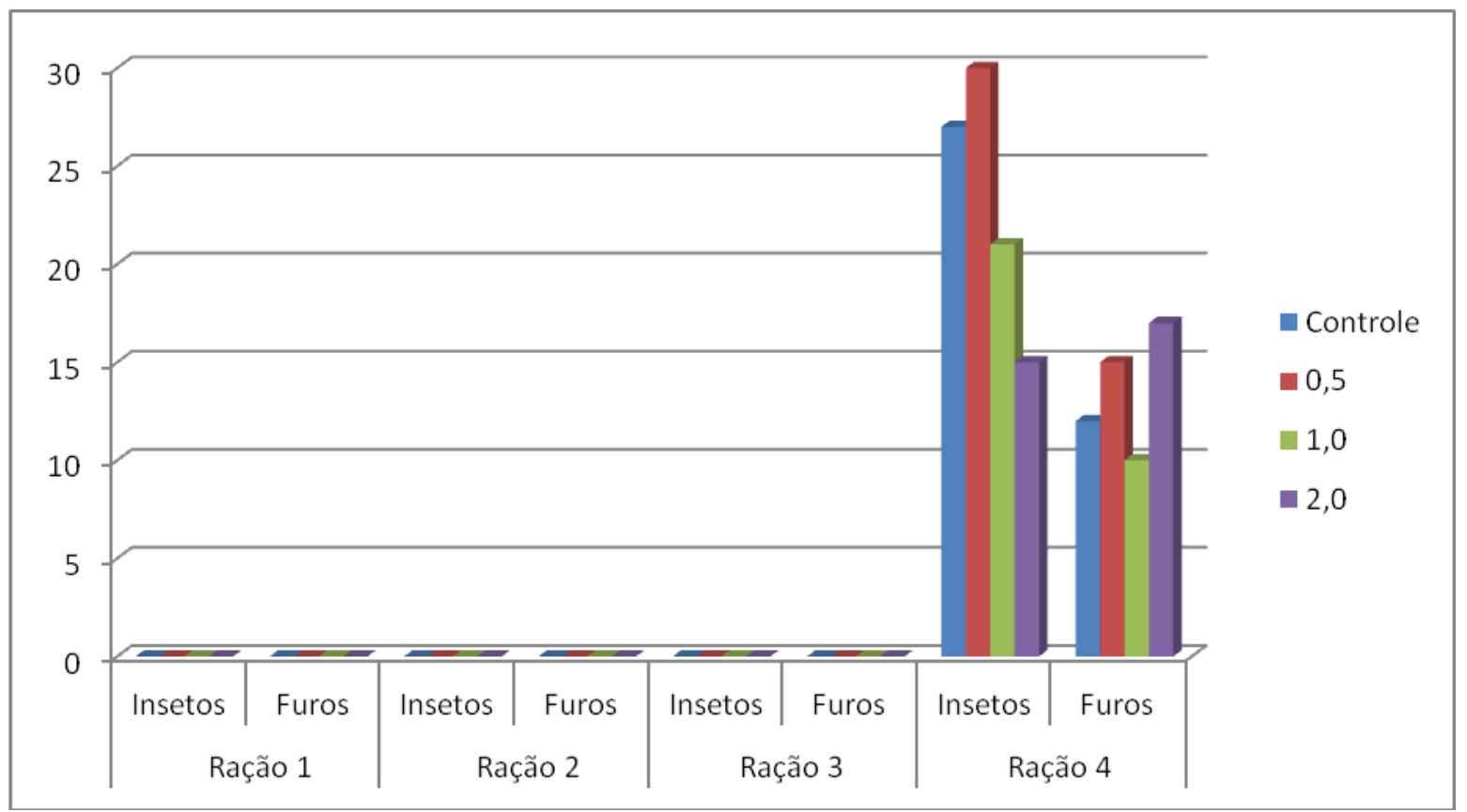

Figura 10. Numero médio de furos e emergência media de adultos de Sitophilus oryzae, provenientes das amostras de rações irradiadas com doses crescentes de radiação gama do Cobalto-60 e submetidas a infestação forçada. 
Tabela 3. Numero médio de furos e emergência media de adultos de Lasioderma serricorne, provenientes das amostras de rações irradiadas com doses crescentes de radiação gama do Cobalto-60 e submetidas a infestação forçada.

\begin{tabular}{|l|cc|cc|cc|cr|}
\hline Doses/kGy & \multicolumn{2}{|c|}{ Ração 1 } & \multicolumn{2}{c|}{ Ração 2 } & \multicolumn{2}{c|}{ Ração 3 } & \multicolumn{2}{c|}{ Ração 4 } \\
& Insetos & Furos & \multicolumn{2}{c|}{ Insetos } & Furos & Insetos & Furos & \multicolumn{2}{c|}{ Insetos } & Furos \\
\hline 0 (controle) & $0,0 \mathrm{a}$ & $0,0 \mathrm{a}$ & $0,0 \mathrm{a}$ & $0,0 \mathrm{a}$ & $0,0 \mathrm{a}$ & $0,0 \mathrm{a}$ & $31,0 \mathrm{a}$ & $17,0 \mathrm{a}$ \\
\hline 0,5 & $0,0 \mathrm{a}$ & $0,0 \mathrm{a}$ & $0,0 \mathrm{a}$ & $0,0 \mathrm{a}$ & $0,0 \mathrm{a}$ & $0,0 \mathrm{a}$ & $10,0 \mathrm{~d}$ & $9,0 \mathrm{~d}$ \\
\hline 1,0 & $0,0 \mathrm{a}$ & $0,0 \mathrm{a}$ & $0,0 \mathrm{a}$ & $0,0 \mathrm{a}$ & $0,0 \mathrm{a}$ & $0,0 \mathrm{a}$ & $24,0 \mathrm{~b}$ & $14,0 \mathrm{~b}$ \\
\hline 2,0 & $0,0 \mathrm{a}$ & $0,0 \mathrm{a}$ & $0,0 \mathrm{a}$ & $0,0 \mathrm{a}$ & $0,0 \mathrm{a}$ & $0,0 \mathrm{a}$ & $17,0 \mathrm{c}$ & $11,0 \mathrm{c}$ \\
\hline
\end{tabular}

Médias seguidas com as mesmas letras não diferem entre si a $5 \%$ de probabilidade pelo teste de Tukey

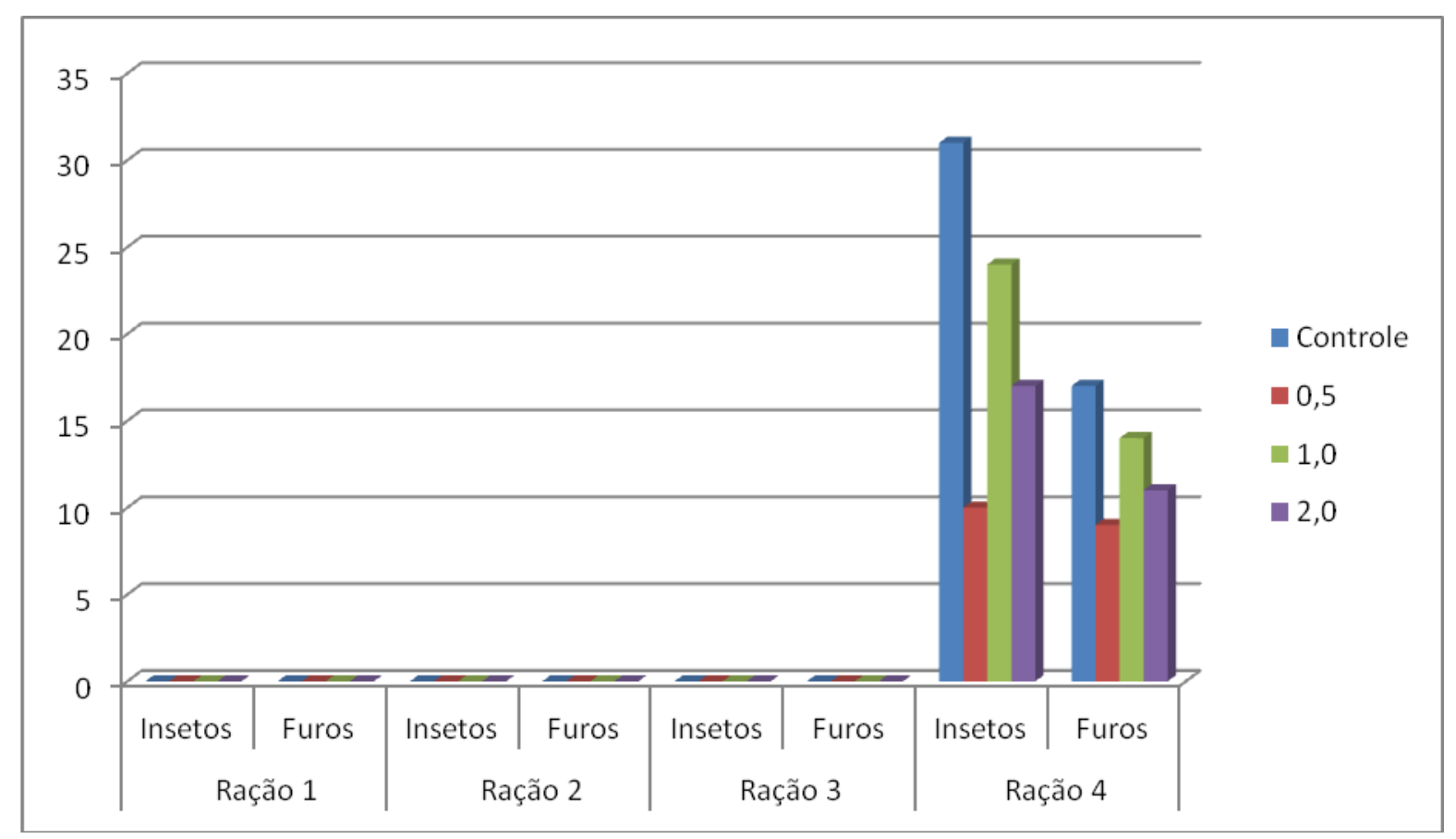

Figura 11. Numero médio de furos e emergência media de adultos de Lasioderma serricorne, provenientes das amostras de rações irradiadas com doses crescentes de radiação gama do Cobalto-60 e submetidas a infestação forçada. 
Tabela 4. Numero médio de furos e emergência media de adultos de Plodia interpunctella, provenientes das amostras de rações irradiadas com doses crescentes de radiação gama do Cobalto-60 e submetidas a infestação forçada.

\begin{tabular}{|l|cc|cc|cc|cc|}
\hline Doses/kGy & \multicolumn{2}{|c|}{ Ração 1 } & \multicolumn{2}{c|}{ Ração 2 } & \multicolumn{2}{c|}{ Ração 3 } & \multicolumn{2}{c|}{ Ração 4 } \\
& Insetos & Furos & Insetos & furos & \multicolumn{2}{c|}{ Insetos } & Furos & \multicolumn{2}{c|}{ Insetos } & Furos \\
\hline 0 (controle) & $0,0 \mathrm{a}$ & $0,0 \mathrm{a}$ & $0,0 \mathrm{a}$ & $0,0 \mathrm{a}$ & $0,0 \mathrm{a}$ & $0,0 \mathrm{a}$ & $24,0 \mathrm{a}$ & $23,0 \mathrm{a}$ \\
\hline 0,5 & $0,0 \mathrm{a}$ & $0,0 \mathrm{a}$ & $0,0 \mathrm{a}$ & $0,0 \mathrm{a}$ & $0,0 \mathrm{a}$ & $0,0 \mathrm{a}$ & $20,0 \mathrm{~b}$ & $19,0 \mathrm{~b}$ \\
\hline 1,0 & $0,0 \mathrm{a}$ & $0,0 \mathrm{a}$ & $0,0 \mathrm{a}$ & $0,0 \mathrm{a}$ & $0,0 \mathrm{a}$ & $0,0 \mathrm{a}$ & $17,0 \mathrm{c}$ & $8,0 \mathrm{~d}$ \\
\hline 2,0 & $0,0 \mathrm{a}$ & $0,0 \mathrm{a}$ & $0,0 \mathrm{a}$ & $0,0 \mathrm{a}$ & $0,0 \mathrm{a}$ & $0,0 \mathrm{a}$ & $15,0 \mathrm{~d}$ & $11,0 \mathrm{c}$ \\
\hline
\end{tabular}

Médias seguidas com as mesmas letras não diferem entre si a $5 \%$ de probabilidade pelo teste de Tukey.

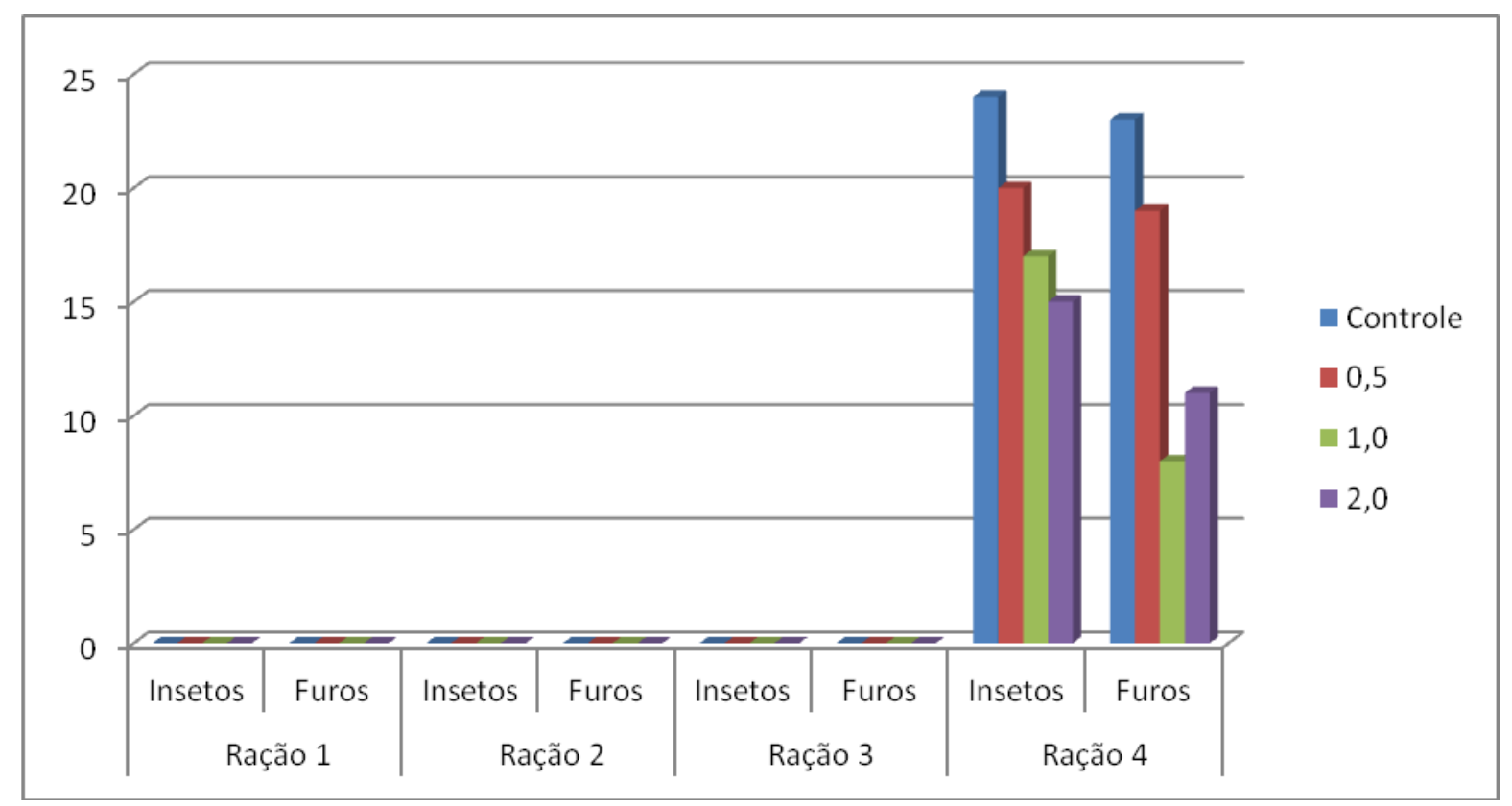

Figura 12. Numero médio de furos e emergência media de adultos de Plodia interpunctella, provenientes das amostras de rações irradiadas com doses crescentes de radiação gama do Cobalto-60 e submetidas a infestação forçada. 
Constam nas Tabelas 5, 6, 7, e 8, os resultados dos ensaios com as rações dos tipos 1, 2, 3 e 4, com os 4 tipos de embalagens que foram infestadas artificialmente com todos as espécies de insetos e fechadas em seladora de acordo com a metodologia de (ARTHUR e ARTHUR 2003; ARTHUR e ARTHUR 2004). Posteriormente foram irradiadas com doses crescentes de radiação gama do Cobalto-60, e avaliadas 60 dias após irradiação. Aguardou-se esse período para que cada espécie de inseto completasse o ciclo evolutivo (ovo a adulto). Para elucidar melhores esses resultados construíram-se as Figuras 13, 14, 15 e 16, onde podemos observar que houve emergência de insetos e numero de furos apenas nos tratamentos controle de todos os tipos de rações.

Pelos resultados dessas tabelas podemos observar que para Sitophilus zeamais, Sitophilus oryzae, Lasioderma serricorne e Plodia interpuctella a dose mínima de radiação gama necessária para induzir a esterilização e consequentemente a desinfestação de todas as amostras de marcas de rações foi a de 0,5 kGy.

Com relação às infestações nos tratamentos controles (isentos de qualquer tratamento), como podemos observar nas referidas tabelas, atingiram um numero relativamente grande de insetos, consequentemente diminuindo proporção de inseto-alimento. Devido a esse problema eles foram obrigados a deixarem às embalagens a procura de novos alimentos. O maior número de furos foi observado justamente nas dobras onde as embalagens foram fechadas, sendo que nestes locais elas apresentam menor resistência ao ataque dos insetos, estando esses resultados de acordo com os encontrados por (WIENDL, et al., 1974; ARTHUR, 1997; RAMOS, 2009; MODOLO, et. al., 2010; ALVEZ, 2011) e próximos aos exigidos pela Agencia Internacional de Energia Atômica ( AIEA) segundo Hallman (2013), que determina uma dose genérica de 0,4 kGy, para a maioria dos insetos pragas de importância agrícola. 
Tabela 5. Numero médio de furos e emergência media de adultos de Sitophilus zeamais, provenientes das amostras de rações infestadas artificialmente e irradiadas com doses crescentes de radiação gama do Cobalto-60.

\begin{tabular}{|c|c|c|c|c|c|c|c|c|}
\hline Doses/kGy & $\begin{array}{r}\text { Raç } \\
\text { Inseto }\end{array}$ & $\begin{array}{l}1 \\
\text { Furos }\end{array}$ & $\begin{array}{r}\text { Raç } \\
\text { Insetc }\end{array}$ & $\begin{array}{l} \\
\text { Euros }\end{array}$ & $\begin{array}{r}\text { Raçá } \\
\text { Inseto }\end{array}$ & $\begin{array}{l}03 \\
\text { Furos }\end{array}$ & $\begin{array}{r}\text { Ração } \\
\text { Insetos }\end{array}$ & $\begin{array}{l}4 \\
\text { Furos }\end{array}$ \\
\hline 0 (controle) & $13,0 b$ & $6,0 b$ & $11,0 b$ & $7,0 b$ & $23,0 b$ & $12,0 b$ & $45,0 b$ & $13,0 b$ \\
\hline 0,5 & $0,0 a$ & $0,0 a$ & $0,0 a$ & $0,0 a$ & $0,0 a$ & $0,0 a$ & $0,0 a$ & $0,0 a$ \\
\hline 1,0 & $0,0 a$ & $0,0 a$ & $0,0 a$ & $0,0 a$ & $0,0 a$ & $0,0 a$ & $0,0 a$ & $0,0 a$ \\
\hline 2,0 & $0,0 a$ & $0,0 a$ & $0,0 a$ & $0,0 a$ & $0,0 a$ & $0,0 a$ & $0,0 a$ & $0,0 a$ \\
\hline
\end{tabular}

Médias seguidas com as mesmas letras não diferem entre si a $5 \%$ de probabilidade pelo teste de Tukey.

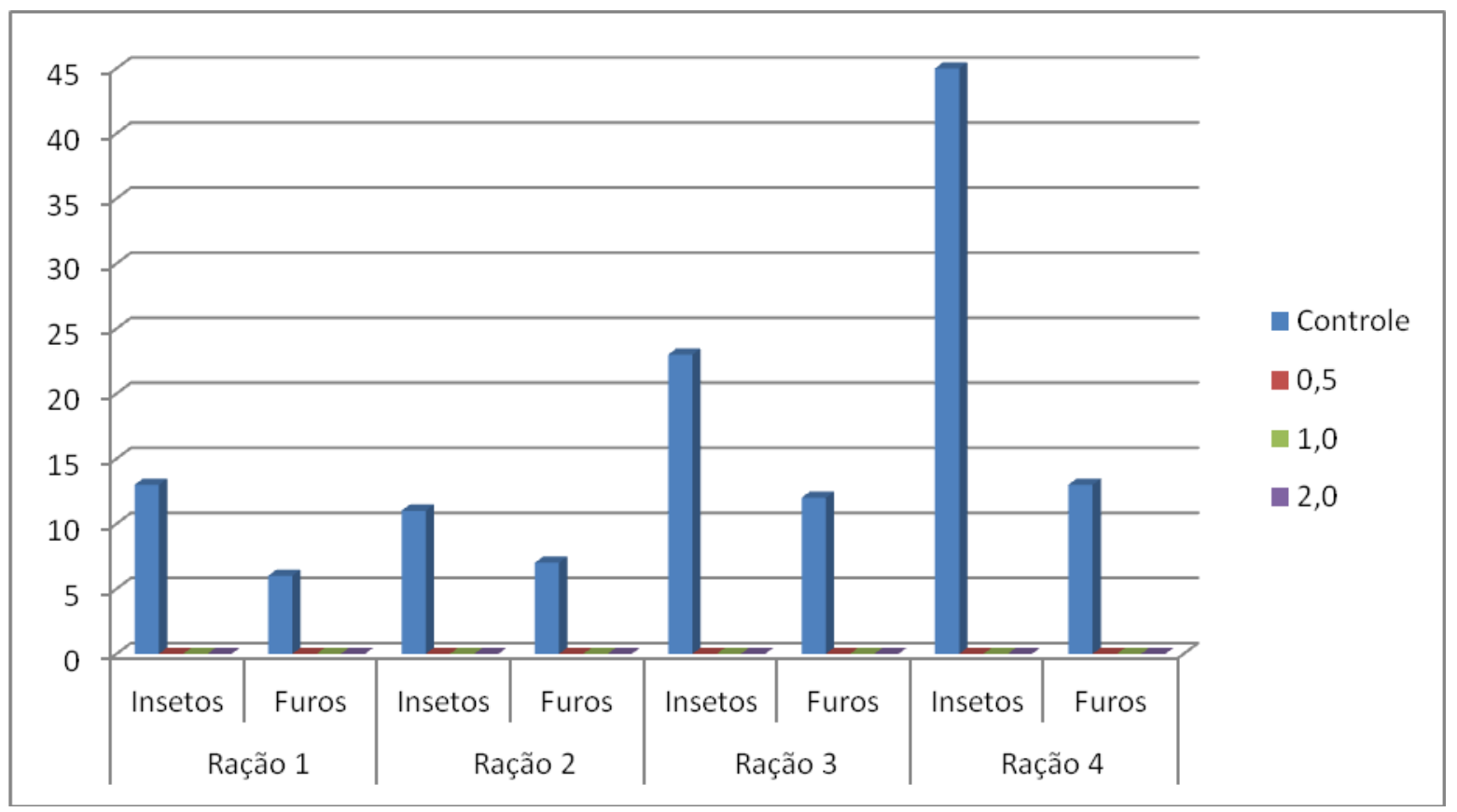

Figura 13. Numero médio de furos e emergência media de adultos de Sitophilus zeamais, provenientes das amostras de rações infestadas artificialmente e irradiadas com doses crescentes de radiação gama do Cobalto-60. 
Tabela 6. Numero médio de furos e emergência media de adultos de Sitophilus oryzae, provenientes das amostras de rações infestadas artificialmente e irradiadas com doses crescentes de radiação gama do Cobalto-60.

\begin{tabular}{|l|cc|cc|cc|cc|}
\hline Doses/kGy & \multicolumn{2}{|c|}{ Ração 1 } & \multicolumn{2}{|c|}{ Ração 2 } & \multicolumn{2}{c|}{ Ração 3 } & \multicolumn{2}{c|}{ Ração 4 } \\
& Insetos Furos & \multicolumn{2}{c|}{ Insetos } & Furos & Insetos & Furos & Insetos & Furos \\
\hline 0 (controle) & $12,0 \mathrm{~b}$ & $7,0 \mathrm{~b}$ & $10,0 \mathrm{~b}$ & $9,0 \mathrm{~b}$ & $16,0 \mathrm{~b}$ & $6,0 \mathrm{~b}$ & $27,0 \mathrm{~b}$ & $11,0 \mathrm{~b}$ \\
\hline 0,5 & $0,0 \mathrm{a}$ & $0,0 \mathrm{a}$ & $0,0 \mathrm{a}$ & $0,0 \mathrm{a}$ & $0,0 \mathrm{a}$ & $0,0 \mathrm{a}$ & $0,0 \mathrm{a}$ & $0,0 \mathrm{a}$ \\
\hline 1,0 & $0,0 \mathrm{a}$ & $0,0 \mathrm{a}$ & $0,0 \mathrm{a}$ & $0,0 \mathrm{a}$ & $0,0 \mathrm{a}$ & $0,0 \mathrm{a}$ & $0,0 \mathrm{a}$ & $0,0 \mathrm{a}$ \\
\hline 2,0 & $0,0 \mathrm{a}$ & $0,0 \mathrm{a}$ & $0,0 \mathrm{a}$ & $0,0 \mathrm{a}$ & $0,0 \mathrm{a}$ & $0,0 \mathrm{a}$ & $0,0 \mathrm{a}$ & $0,0 \mathrm{a}$ \\
\hline
\end{tabular}

Médias seguidas com as mesmas letras não diferem entre si a $5 \%$ de probabilidade pelo teste de Tukey.

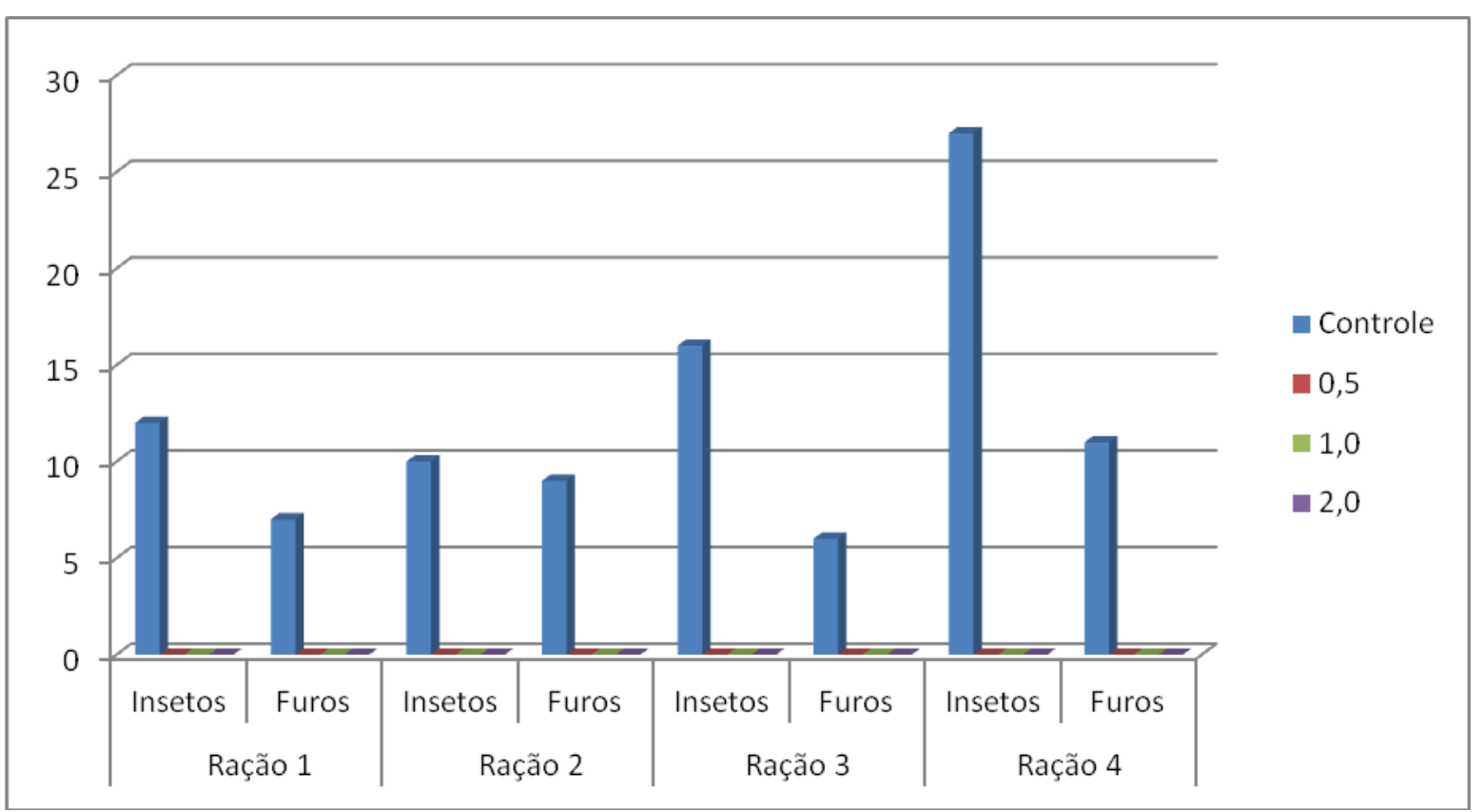

Figura 14. Numero médio de furos e emergência media de adultos de Sitophilus oryzae, provenientes das amostras de rações infestadas artificialmente e irradiadas com doses crescentes de radiação gama do Cobalto-60. 
Tabela 7. Numero médio de furos e emergência media de adultos de Lasioderma serricorne, provenientes das amostras de rações infestadas artificialmente e irradiadas com doses crescentes de radiação gama do Cobalto-60.

\begin{tabular}{|l|cc|cc|cc|cc|}
\hline Doses/kGy & \multicolumn{2}{|c|}{ Ração 1 } & \multicolumn{2}{|c|}{ Ração 2 } & \multicolumn{2}{c|}{ Ração 3 } & \multicolumn{2}{c|}{ Ração 4 } \\
& \multicolumn{2}{|c|}{ Insetos Furos } & \multicolumn{2}{|c|}{ Insetos } & Furos & Insetos & Furos & \multicolumn{2}{c|}{ Insetos Furos } \\
\hline 0 (controle) & $18,0 \mathrm{~b}$ & $9,0 \mathrm{~b}$ & $13,0 \mathrm{~b}$ & $11,0 \mathrm{~b}$ & $13,0 \mathrm{~b}$ & $8,0 \mathrm{~b}$ & $49,0 \mathrm{~b}$ & $17,0 \mathrm{~b}$ \\
\hline 0,5 & $0,0 \mathrm{a}$ & $0,0 \mathrm{a}$ & $0,0 \mathrm{a}$ & $0,0 \mathrm{a}$ & $0,0 \mathrm{a}$ & $0,0 \mathrm{a}$ & $0,0 \mathrm{a}$ & $0,0 \mathrm{a}$ \\
\hline 1,0 & $0,0 \mathrm{a}$ & $0,0 \mathrm{a}$ & $0,0 \mathrm{a}$ & $0,0 \mathrm{a}$ & $0,0 \mathrm{a}$ & $0,0 \mathrm{a}$ & $0,0 \mathrm{a}$ & $0,0 \mathrm{a}$ \\
\hline 2,0 & $0,0 \mathrm{a}$ & $0,0 \mathrm{a}$ & $0,0 \mathrm{a}$ & $0,0 \mathrm{a}$ & $0,0 \mathrm{a}$ & $0,0 \mathrm{a}$ & $0,0 \mathrm{a}$ & $0,0 \mathrm{a}$ \\
\hline
\end{tabular}

Médias seguidas com as mesmas letras não diferem entre si a $5 \%$ de probabilidade pelo teste de Tukey.

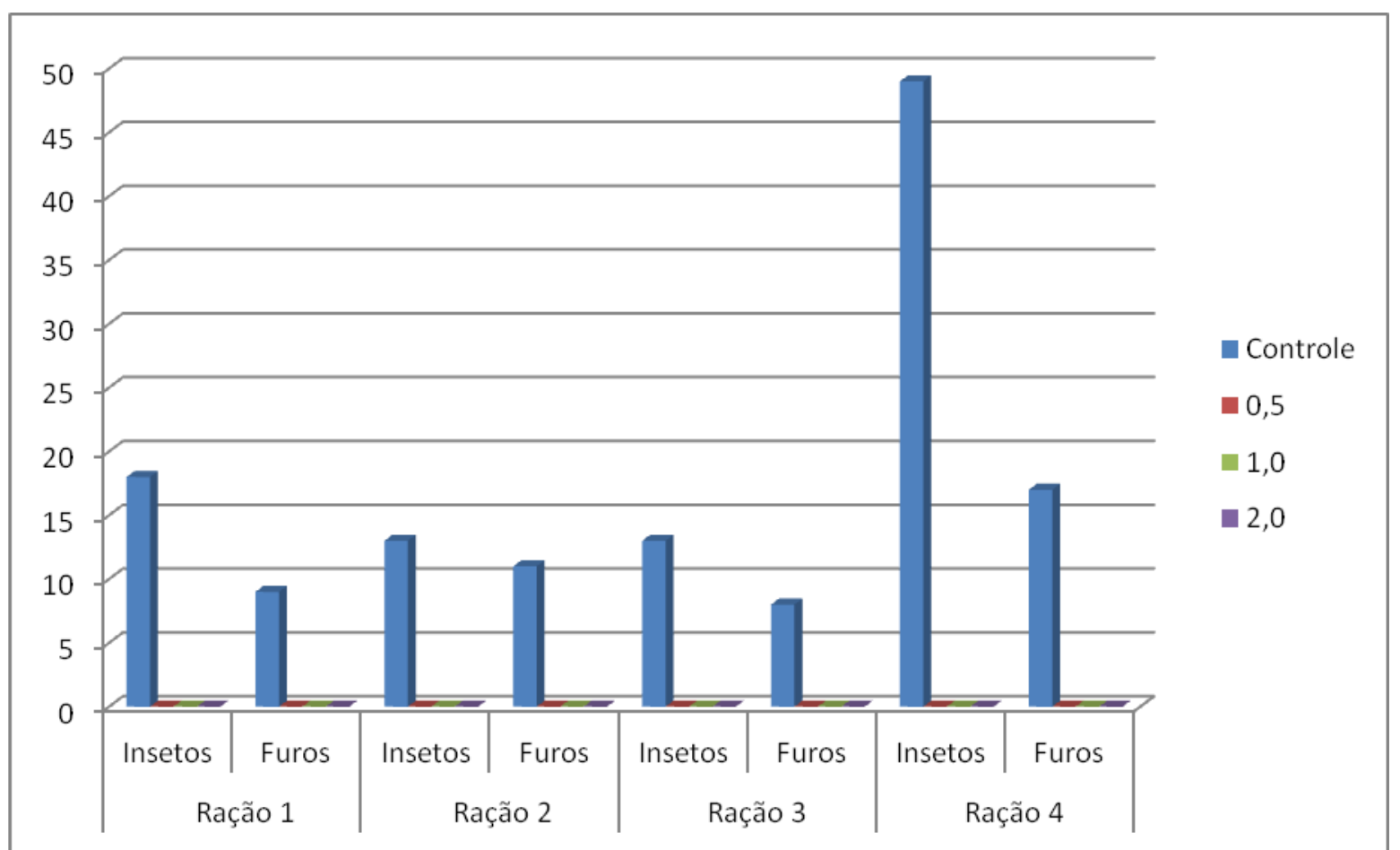

Figura 15. Numero médio de furos e emergência media de adultos de Lasioderma serricorne, provenientes das amostras de rações infestadas artificialmente e irradiadas com doses crescentes de radiação gama do Cobalto-60. 
Tabela 8. Numero médio de furos e emergência media de adultos de Plodia interpunctella, provenientes das amostras de rações infestadas artificialmente e irradiadas com doses crescentes de radiação gama do Cobalto-60.

\begin{tabular}{|c|c|c|c|c|c|c|c|c|}
\hline \multirow{2}{*}{ Doses/kGy } & \multicolumn{2}{|c|}{ Ração 1} & \multicolumn{2}{|c|}{ Ração 2} & \multicolumn{2}{|c|}{ Ração 3} & \multicolumn{2}{|c|}{ Ração 4} \\
\hline & Insetos & Furos & Insetos & Furos & Insetos & Furos & Insetos & Furos \\
\hline 0 (controle) & $15,0 \mathrm{~b}$ & $9,0 \mathrm{~b}$ & $20,0 b$ & $11,0 b$ & $17,0 \mathrm{~b}$ & $7,0 \mathrm{~b}$ & $22,0 \mathrm{~b}$ & $13,0 \mathrm{~b}$ \\
\hline 0,5 & $0,0 a$ & $0,0 a$ & $0,0 a$ & $0,0 \mathrm{a}$ & $0,0 a$ & $0,0 \mathrm{a}$ & $0,0 \mathrm{a}$ & $0,0 a$ \\
\hline 1,0 & $0,0 a$ & $0,0 a$ & $0,0 a$ & $0,0 \mathrm{a}$ & 0,0 & $0,0 \mathrm{a}$ & $0,0 \mathrm{a}$ & $0,0 a$ \\
\hline 2,0 & $0,0 a$ & $0,0 a$ & $0,0 a$ & $0,0 \mathrm{a}$ & 0,0 & $0,0 \mathrm{a}$ & $0,0 \mathrm{a}$ & $0,0 a$ \\
\hline
\end{tabular}

Médias seguidas com as mesmas letras não diferem entre si a $5 \%$ de probabilidade pelo teste de Tukey.

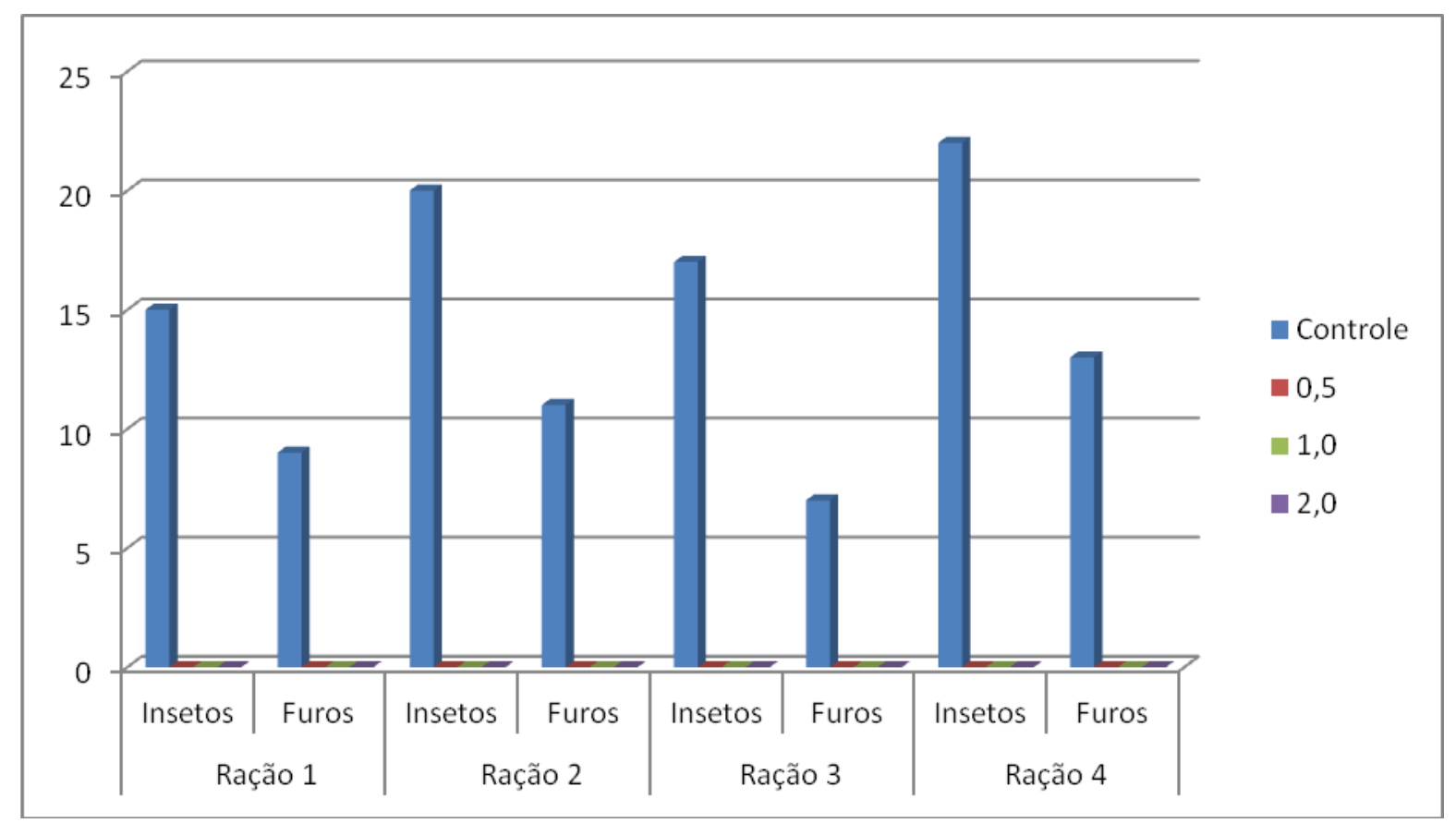

Figura 16. Numero médio de furos e emergência media de adultos de Plodia interpunctella, provenientes das amostras de rações infestadas artificialmente e irradiadas com doses crescentes de radiação gama do Cobalto-60. 
Com relação aos danos causados pelas radiações ionizantes nos alimentos, ele é maior naqueles que apresentam maiores teores de umidade. Isso por que ocorre maior formação de radicais livres que interagem entre si formando peroxilas que são prejudiciais ás células dos organismos. Estando de acordo com (ARTHUR et al., 2012) que afirmam que quanto menor for o teor de umidade nos grãos e rações, menores são os danos causados pelas radiações ionizantes. Com relação aos insetos podemos observar que todas as espécies foram sensíveis as radiações gama e uma dose de 0,5 kGy foi suficiente para controlar todas as espécies, pois uma população estéril é uma população extinta (ARTHUR, 1997).

Convém ressaltar também a importância da embalagem, porque não resolve somente fazer o tratamento quarentenário de pragas pelo processo de irradiação, se a embalagens não forem resistentes. Como foi o caso da embalagem da ração número 4, que não impediu a reinfestação, os insetos penetraram nessa embalagem e se desenvolveram normalmente nessa ração. $O$ ideal seria fazer o controle integrado da irradiação e produtos químicos, porque um completa o outro, levando a uma eficiência de 100\% no controle dos insetos (ARTHUR et al., 2012). 


\section{CONCLUSÕES}

Pelos resultados obtidos pode-se concluir que:

- A embalagem da ração tipo número 4, foi á única susceptível ao ataque de todas as espécies de insetos estudadas.

- A menor dose de radiação gama utilizada 0,5 kGy, foi suficiente para induzir a esterilização e consequentemente a desinfestação de todas as espécies de insetos pragas nas rações estudadas. 


\section{REFERÊNCIAS BIBLIOGRÁFICAS}

ABC DA FISICA NUCLEAR - CENTRO DE DESENVOLVIMENTO DA TECNOLOGIA NUCLEAR. Disponível em: < http://www.dfn.if.usp.br/paginadfn/divulgacao/abc/Basic.html\#Gammadecay>. Acesso em: 25 abril, 2012.

ALMEIDA, A. A.; POY, L. D. A. Reprodução de Rhyzopertha dominica (F., 1792) (Coleoptera, Bostrychidae) em grãos inteiros, partidos, de cultivares de trigo, de textura vítrea e suave. Revista Brasileira de Entomologia, v. 8, p. 599-604, 1994.

ALVES, J. N. Utilização da radiação gama do cobalto-60 como tratamento quarentenário de plantas medicinais, aromáticas e condimentares desidratadas infestadas por Lasioderma serricorne e Plodia interpunctella. 2007. Dissertação (Mestrado) - Instituto de Pesquisas Energéticas e Nucleares, São Paulo. 79p.

ALVES, J. N. Avaliação dos efeitos da radiação por feixe de elétrons na resistência de embalagens a Lasioderma serricorne e Plodia interpunctella e Sitophilus zeamais 2011. Tese (Doutorado) - Instituto de Pesquisas Energéticas e Nucleares, São Paulo. 103p.

ARTHUR, V. Efeitos esterilizantes e letais das radiações gama nas diferentes fases do ciclo evolutivo de Sitotroga cerealella em arroz e milho. Tese (Doutorado) Escola Superior de Agricultura "Luiz de Queiroz" Universidade de São Paulo, 77p. 1985.

ARTHUR, V. Controle de insetos-pragas por radiações ionizantes. Biológico, São Paulo, v.59, n.1, p.77-79, 1997.

ARTHUR, V.; ARTHUR, P. B. Teste de Resistência de algumas embalagens para feijão ao ataque de Zabrotes subfasciatus. I CONGRSSO DE INICIAÇÃO 
CIENTIFICA EM CIENCIAS AGRÁRIAS, BIOLOGICAS E AMBIENTE. Instituto Biológico, São Paulo, pg. 4, 2003.

ARTHUR, V.; ARTHUR, P. B. Resistência de embalagens para feijão irradiado ao ataque de Acanthoscelides obtectus. XX CONGRESSO BRASILEIRO DE ENTOMOLOGIA, Gramado, RS., pg. 549, 2004.

ARTHUR, V.; WIENDL, F. M.; PACHECO, J.M.; WALDER, J.M.M.; SCRILLO, R.B. Mortalidade e reprodução de Sitophilus zeamais, Mots. Em macarrão irradiado In: USO Y CALIBRACION DE FUENTES INTENSAS DE RADIACION, 18-22 de jun., 1973, Santiago Informe del Seminario Santiago., 10p.,1973.

ARTHUR, V.; ARTHUR, P. B.; GAVA, M. A.; FRANCO, S. S. H.; MACHI, A. R. Uso de técnicas nucleares em entomologia no Brasil. In: BUSOLI, A. C.; GRIGOLLI, J. F. J.; SOUZA, L. A.; KUBATA, M. M.; COSTA, E. N.; SANTOS, L. A. O.; NETTO, J. C.; VIANA, M. A. Tópicos em entomologia agrícola V. Jaboticabal: Gráfica e Editora Multipress. p. 13-25, 2012.

BARBOSA, D. R. S. Efeitos da radiação micro-ondas nas diferentes fases do ciclo evolutivo de Callosobruchus maculatus (Fabr., 1775) (Coleoptera: Bruchidae) visando o seu controle em feijão caupi. Dissertação - Universidade Federal do Piauí, Teresina, Piauí, 2010, 89p.

BIOCONTROLE - Métodos de Controle de Pragas. Disponível em:< http://www.biocontrole.com.br/pragas/lasioderma serricorne.php> Acesso em: 07 maio. 2012.

BUCHALLA, R.; BOESS, C.; BÖGL, K.W. Characterization of Volatile Radiolysis Products in Radiation-Sterilized Plastics by Thermal Desorption-Gas Chromatography-Mass Spectrometry: Screening of Six Medical Polymers. Radiation Physics and Chemistry, v.56, p.353-367, 1999. 
BUCHALLA, R.; SCHÜTTLER, C.; BÖGL, K.W. Effects of Ionizing Radiation on Plastic Food Packaging Materials: A Review, Part 1, Chemical and Physical Changes. Journal of Food Protection, v.56, n.11, p.991-997, 1993.

BORROR, D. J.; DELONG, D. M. An Introduction to the Study of Insects. USA: HOLD RINEHART WINSTON, 1964. 819p.

CARCIOFI, A. C.; VASCONCELlOS, R. S.; BORGES, N. C.; MORO, J. V.; PRADA, F.; FRAGA, V. O. Composição nutricional e avaliação de rótulo de rações secas para cães comercializadas em Jaboticabal-SP. Arquivos Brasileiro Medicina Veterinária Zootecnia., v.58, n.3, p.421-426, 2006.

CAMPOS, T. B. Pragas dos Grãos Armazenados. In: REUNIÃO ITINERANTE DE FITOSSANIDADE DO INSTITUTO BIOLÓGICO DO INSTITUTO BIOLOGICO, 24-25 de set. 2005, Ribeirão Preto. ANAIS DA XII REUNIÃO ITINERANTE DE FITOSSANIDADE DO INSTITUTO BIOLÓGICO, Ribeirão Preto: Instituto Biológico, 2005. p. 5-12.

CAMPOS, T. B; ZORZENON, F. J. Pragas dos Grãos e Produtos Armazenados. Boletim Técnico: Instituto Biológico, São Paulo, 27p. 2006.

CENA - Centro de Energia Nuclear na Agricultura da Universidade de São Paulo. Disponível em: < http://www.cena.usp.br/irradiacao/index.asp> Acesso em: 03 mai. 2012.

CELARO, J. C. Métodos curativos de controle de pragas de grãos armazenados. In: LORINI, I.; MIIKE, L. H.; VILDES, M. S. (Eds.) Armazenagem de Grãos. Campinas: IBG, p. 493-529, 2002.

CLOUGH, R. L.; GILLEN K, T.; MALONE, G. M.; WALLACE, J. S. Color Formation in Irradiated Polymers. Radiation Physics and Chemistry, v.48, n.5, p.583-594, 1996. 
CSIRO - Plodia interpunctella. Disponível em < ttp://sgrl.csiro.au/storage/insects/beetles moths/Plodia interpunctella.html> Acesso em: 26 mai. 2012.

CAVAlCANTI, P.; CHAGAS, C. História da Embalagem no Brasil. São Paulo. Abre Associação Brasileira de Embalagem, 2006.

DELINCÉE, H.: VILLAVICENCIO, A. L. C. H.; MANCINI-FILHO, J. Protein quality of irradiated Brazilian beans. Radiation Physics Chemistry, v. 52:1-6, p. 43-48, 1998.

DIEHEL, J. F. Food irradiation: is an alternative to chemical preservations. Food Addition Contaminants. v. 9, p.409-416, 1992.

DIEHL, J. F.; JOSEPHSON, E. S. Assessment of wholesomeness of irradiated food: a review. Acta Alimentaria., n. 2, v. 23, p.195-214, 1994.

DIEHL, J. F. Safety of irradiated foods. 2ed. New York: Marcel Dekker Inc., p91115, 1995.

EMBRARAD - EMPRESA BRASILEIRA DE RADIAÇÃO. Disponível em: <http://www.embrarad.com.br/alimentos.asp > Acesso em: 07 mai. 2012.

FOLLETT, P. A.; ESNOOK, K.; JANSON, A.; ANTONIO, B.; HARUKI, A.; OKAMURA, M.; BESEL, J. Irradiation quarantine treatment for control of Sitophilus oryzae (Coleoptera: Curculionidae) in rice. Journal Stored Products Research, v. 52, 63-67, 2013.

FRKAS, J. Principios de la irradiación de alimentos. In: LA IRRADIACIÓN DE ALIMENTOS EN LATINOAMÉRICA, octubre 24-28, 1983, Lima, Perú. Proceedings. Vienna,: OIEA, p. 11-23. 1993.

GALLO, D.; NAKANO, O.; WIENDL, F. M.; SILVEIRA NETO, S.; CARVALHO R. P. L. Manual de entomologia. São Paulo: Agronômica Ceres, 1970, 531p. 
GALLO, D.; NAKANO, O.; SILVEIRA NETO, S.; CARVALHO, R. P. L.; BATISTA, G. C. de; BERTI FILHO, E.; PARRA, J. R. P.; ZUCCHI, R. A.; ALVES, S. B.; VENDRAMI, J.D. Manual de Entomologia Agrícola. 2.ed. São Paulo: Agronômica Ceres, 1988, 680p.

GALLO, D.; NAKANO, O.; SILVEIRA NETO, S.; CARVALHO R. P. L.; BATISTA, G. C. de; BERTI FILHO, E.; PARRA, J. R. P.; ZUCCHI, R. A.; ALVES, S. B.; VENDRAMI, J.D; MARCHINI, L. C.; LOPES, J.R.S.; OMOTO, C. Entomologia Agrícola. Piracicaba: FEALQ, 2002, 890p.

GITZ, A.; REZENDE, A. C de; MENEZES NETO, M. Y. Armadilhas com feromônio: uma ferramenta auxiliar no manejo integrado de pragas. In: LORINI, I.; MIIKE, L. H.; VILDES, M. S. (Eds.) Armazenagem de grãos. Campinas: IBG, p. 595- 605, 2002.

GURKIN, A. H. The pet food report. Pet food Industry. South Africa, v. 6, p. 26-32, 2001.

HALLMAN, G. J. Control stored product pests by ionizing radiation. Journal Stored Products Research, v. 52, 36-41, 2013.

HAINES, C. P.; PRANATA, R. I. Survey on insects and arachnids associated with stored products in some parts of Java. In: TETER, N.C.; FRIO, A. S. (Eds) Progress in grain protection, PROCEEDINGS $5^{\text {th }}$ ANNUAL WORKSHOP In: GRAIN POSTHARVEST RESEARCH AND DEVELOPMENT PROGRAMME, Laguna, Philippines, p 17-48, 1982.

HERBARIO. Disponível em: < http://www.herbario.com.br/dataherb13/2312racaopet.htm>. Acesso em 20 nov. de 2012

HOUSSAIN, M. M.; BROWER, J. H.; TILTON, E. W. Sensitivity to an acute gamma radiation exposure of successively irradiated generations of the cowpea weevil. Journal Economic Entomology, v. 65, n. 6, p.1566-1568, 1972. 
HUNTER, W. D. Results of experiments to determine the effects of roentgen upon insects. Journal Economic Entomology, v. 5, p. 118, 1912.

http://www.termapest.co.uk/id17.html - Lasioderma serricorne. Acesso em: 26 mai. 2012.

http://www.amiciinsoliti.it/cibovivo/sitophilus.html - Sitophilus oryzae. Acesso em: 26 mai. 2012.

INTERNATIONAL ATOMIC ENERGY AGENCY (IAEA). Training manual on food irradiation technology and techniques, 1982, Vienna, 2. ed., Technical Reports, n. 114, 1982.

JACKMAN, J. A - Sitophilus zeamais - Disponível em $<$ cts.tamu.edu/youth/4H/studymaterials/intermediate/taxalist2/ibug050.html> Acesso em: 26 mai. 2012.

JUNIOR, A. A. R. de.; POTENZA, M. R.; CIARLARIELLO, B. G. F. de.; AQUINO, S.; VIEIRA, S. V. dos. Irradiação de Alimentos: Efeitos no Sistema Biológico. 2002. (Monografia) - Instituto de Pesquisas Energéticas e Nucleares, São Paulo.

KURTZ, O. L.; HARRIS, K. L. Micro-analytical Entomology for Food Sanitation Control. Washington: Association of Official Agricultural Chemists, 77p.,1962.

LORIN, I.; SCHNEIDER, S. Pragas de grãos armazenados. Passo Fundo: EMBRAPA-CNPT, 85p,1994.

LORINI, I. Manual técnico para o manejo integrado de pragas de grãos de cereais armazenados. Passo Fundo: Embrapa Trigo, 75p., 2001.

LORINI, I. (a) Manejo integrado de pragas de grãos armazenados. In: LORINI, I.; MIIKE, L. H.; VILDES, M. S. (Eds.). Armazenagem de grãos. Campinas: IBG, p. 607-621, 2002 
LORINI, I. (b) Insetos Pragas em Grãos Armazenados. In: LORINI, I.; MIIKE, L. H.; VILDES, M. S. (Eds.). Armazenagem de grãos. Campinas: IBG, p. 381-397, 2002.

LORINI, I.; KRZYZANOWSKI, F. C.; FRANÇA-NETO, J. B.; HENNING, A. A. Principais pragas e métodos de controle em sementes durante o armazenamento. Circular Técnica, Embrapa, 2010, 10p.

MADI, L. A. Embalagem no Século xxi - Perspectivas e Tendências. Brasil Pack Trends 2005 - Embalagem, Distribuição e consumo Ed. 2000, p. 1-17, 2000.

MAGALHÃES, B. P.; CARVALHO, S. M. de. Insetos associados à cultura. In: ZIMMERMANN, M. J. de O.; ROCHA, M.; YAMADA, T. (Eds.). Cultura do feijoeiro: fatores que afetam a produtividade. Piracicaba: Associação Brasileira para a Pesquisa da Potassa e do Fosfato, p. 573-589, 1998.

MANEJO INTEGRADO DE PRAGAS DE PRODUTOS ARMAZENADOS Universidade Federal de Lavras. Disponível em: $<$ http://www.den.ufla.br/Professores/Ronald/Disciplinas/Notas\%20Aula/Praga\%20gra os\%20armazenados.pdf.> Acesso em: 09 de abril. 2012.

MARCOTTE, M. Effect of irradiation on spices, herbs and seasoning: Comparasion with ethylene oxide fumigation. Disponivel em: < http://www.foodirradiation.com/Spices.htm>. Acesso em: 15 de nov. 2012.

MELLO, L. C. de. Irradiação de alimentos. São Paulo: EDUSP, 56p., 2000.

MESTRINER, F. Novos hábitos exigem novas embalagens. Disponível em: < http://www.portaldapropaganda.com/design/abre >. Acesso em 15 agost.. 2012.

MODOLO, D. M.; OLIVEIRA, A. C. S.; SILVA, L. C. A. S.; ARTHUR, P. B.; LIMA, R. B.; ARTHUR, V. Influencia da embalagem e radiação gama no tratamento 
quarentenário de Sitophilus oryzae em arroz. Biológico, São Paulo, v.71, n. 2 p. 83202, 2009.

MONK, J. D.; BEUCHAT, L. R.; DOYLE, M. R. Irradiation inactivation of food-borne microorganisms. Jounal Food Protection, Ames, v. 58, n. 2, p.197-208, 1995.

MÜNZNER, R. Some factors affecting the radio sensitivity of molds (in Geman). Archives Mikrobiologi., v. 64, p. 349-356, 1969.

MOUND, L. Common insect pest of stored food products: a guide to their identification. British Museum (Natural History), 156p., 1989.

MOURA, R. A.; BANZATO, J. M. Embalagem, Unitização \& Conteinerização Manual de Logística. v.3, 4 ed. São Paulo, 175p., 2003.

MOURA, E. A. B. Avaliação do desempenho de embalagens para alimentos quando submetidos a tratamento por radiação ionizante. 2006. Tese (Doutorado) Instituto de Pesquisas Energéticas e Nucleares. 85p. 2006.

MOURA, E. A. B.; ORTIZ, A. V.; WIEBECK, H.; PAULA, A. B. A.; SILVA, A. L. A.; ANDRADE, S. L. G. Effects of Gamma Radiation on Commercial Food Packaging Films - Study of Changes UVIVIS Spectra. Radiation Physics and Chemistry. v. 71, p.199-202, 2004.

O'DONNELL, J.H. \& SANGSTER, D. F. Principles of Radiation Chemistry. New York, N.Y.: Ed. Arnold, 278p. 1970.

PACHECO, I. A.; PAULA, D. C. de. Insetos de grãos armazenados: identificação e biologia. Campinas: Fundação Cargill, 67p., 1995.

PLATZER, N. A. J. Irradiation of Polymers. Washington, Wash.: American Chemical Society, 90p. 1967. 
RAMOS, A. C. O. Aplicação da radiação gama na desinfestação de rações a base de grãos para alimentação de animais domésticos. 2009. Dissertação (Mestrado) - Instituto de Pesquisas Energéticas e Nucleares - São Paulo, 68p.

RAMOS, A. C. O. ; POTENZA, M. R. ; ARTHUR, V. . Quarantine treatment for Sitophilus zeamais (Coleoptera: Curculionidae) though of the gamma radiation of Cobalt-60. In: INTERNATIONAL NUCLEAR ATLANTIC CONFERENCE - INAC 2009, 2009, Rio de Janeiro. 2009 INTERNATIONAL NUCLEAR ATLANTIC CONFERENCE - INAC 2009, 2009.v. 1, p. 76.

RAMOS, A. C. O. ; POTENZA, M. R. ; ALVES, J.N.A. ; ARTHUR, V. ; JUSTI JÚNIOR, J.E Utilization of gamma radiation of Coalt-60 for disinfestations of Lassioderma serricorne (Fabricius, 1972)(Coleoptera: Anobiidae) in Cymbopogon citratus stapf and Ocimun basillicum L.deydrated. In: INTERNATIONAL NUCLEAR ATLANTIC CONFERENCE - INAC 2007, 2007, Santos. 2007 I INTERNATIONAL NUCLEAR ATLANTIC CONFERENCE - INAC 2007, 2007. v. 1. P. 234.

RUDAVETS, J.; SALAS, I.; PONS, M. J. Demage characterisitics produced by insect pest in packaging film. Journal Stored Products Research.., v. 43, p. 564-570, 2007.

RUNNER, G. A. Effects of roentgen rays on the tobacco or cigarette beetle and results of experiments with a new form of roentgen tube. Journal Agriculture Research., v. 6, n. 11, p. 383-388, 1916.

SANTIN, M. The case of food irradiation. International Conference of the Agricultural Research Institute, p. 93-110, 1993.

SANTOS, J. P. dos. Métodos preventivos de controle de pragas de grãos armazenados. In: LORINI, I.; MIIKE, L. H.; VILDES, M. S. (Eds.). Armazenagem de Grãos. Campinas: IBG, 399-441, 2002. 
SEN, M.; BASFAR, A. A. The Effect of UV Light on the Thermooxidative Stability of Linear Low Density Polyethylene Films Crosslinked by Ionizing Radiation. Radiation Physics and Chemistry. v.52, p.247-250, 1998.

SINDIRAÇÕES. Disponível em; < http://www.sindiracoes.com.br> Acesso em 20 de abril de 2012

TECNIGRAN. Disponível em: < http://www.tecnigran.com.br>. Acesso em: 10 abril. de 2012.

VILLAVICENCIO, A. L. C. H. Avaliação dos efeitos da radiação ionizante de Cobalto-60 em propriedades fisicas, quimicas e nutricionais dos feijões Phaseolus vulgaris L. e Vigna unguiculata L . 1998. Tese (Doutorado) Faculdade de Ciências Farmacêuticas da Universidade de São Paulo, São Paulo. 98p.

WIENDL, F. M.; ARTHUR, V.; PACHECO, J. M.; SGRILLO, R. B.; WALDER, J. M. M. Mortalidade e reprodução de Sitophilus zeamais (M) em milho pré-irradiado. In: USO Y CALIBRACION DE FUENTES INTENSAS DE RADIACION, 18-22 de jun., 1973, Santiago Informe del Seminario Santiago., 8p., 1973.

WIENDL, F. M.; PACHECO, J. M.; WALDER, J. M. M. SGRILLO, R. B.; DOMARCO, R. E. A method of determining the gamma radiation doses for sterilization. Sterility for Control. IAEA, p. 289-315, 1974.

ZUCCHI, R. A.; SILVEIRA NETO, S.; NAKANO, O. Guia de identificação de pragas agrícolas. Piracicaba: FEALQ, 154p., 1993.

WHO - WORLD HEALTH ORGANIZATION; INTERNATIONAL ATOMIC ENERGY AGENCY; FOOD AND AGRICULTURE ORGANIZATION OF THE UNITED NATIONS. High-Dose Irradiation: Wholesomeness of Food Irradiation With Dose Above 10 kGy. Report of a Joint FAO/IAEA/WHO Expert Committee. Geneva, World Health Organization, 1999 (WHO Technical Report Series, No 890). 